\title{
Effect of Numerical Soil-Foundation-Structure Modeling on the Seismic Response of a Tall Bridge Pier via Pushover Analysis
}

\author{
M. R. Falamarz-Sheikhabadi ${ }^{1 *}$ and A. Zerva ${ }^{2}$
}

\begin{abstract}
This paper examines the role of the numerical modeling of soil-foundation-structure (SFS) interaction on the seismic response of a tall, partially embedded, flared bridge pier. For this purpose, static, pushover, nonlinear, finite-element, stand-alone analyses are performed on nine different models of one of the two piers of the Mogollon Rim Viaduct, a long-span, reinforcedconcrete bridge supported on pile foundations. Structural modeling considerations, such as selection of concrete constitutive models, material properties, and bond-slip and P- $\Delta$ effects, on the nonlinear response of this pier are investigated. $p-y, t-z$ and $Q-z$ nonlinear curves are applied to model the soil-pile interaction, and equivalent nonlinear springs are developed to reproduce the soil-pile cap interaction. In addition, the effects of the partial pier embedment and the slope of the ground surface on the lateral resistance of the pier and the total capacity of the SFS system are examined. The results illustrate how structural and geotechnical modeling approaches for the SFS interaction can affect the nonlinear response of tall bridges, and may lead to differences in the numerical prediction of local or global failure. For the case analyzed herein, the partial pier embedment and foundation flexibility can dramatically modify the structural response, and influence the bond-slip effect at the pier-pile cap connection.
\end{abstract}

Keywords: Pushover analysis; Model uncertainty; Bond slip; P- $\Delta$ effect; Soil-foundationstructure interaction; Partial Pier embedment; Pile cap; Pile group; Ground surface slope.

\footnotetext{
${ }^{1}$ PhD Candidate, Dept. of Civil, Architectural \& Environmental Engineering, Drexel University, Philadelphia, PA

${ }^{2}$ Professor, Dept. of Civil, Architectural \& Environmental Engineering, Drexel University, Philadelphia, PA

${ }^{*}$ Corresponding Author; phone: 215-264-8909; e-mail: $\underline{\text { mf585@drexel.edu }}$
} 


\section{Introduction}

One of the challenging problems in earthquake engineering is the consideration of the soil-foundationstructure (SFS) interaction on the seismic behavior of structures. For single-support structures, the SFS interaction changes the dynamic properties of the system (dynamic effects) and modifies the foundation input motions (kinematic effects) [1], [2]. For multiple-support structures, in addition to the two aforementioned effects, it may induce significant pseudo-static forces in the structure [3], [4], [5], and results in amplification of the contribution of the higher modes to the seismic response. As a consequence, the consideration of an appropriate finite-element model for the SFS system of long-span bridges, which are most sensitive to pseudo-static excitations [6], plays an important role in their reliable seismic assessment [4]. At the present time, this consideration is still an issue for the safe seismic design of bridges supported on pile foundations because: (1) the provisions of bridge design codes, such as AASHTO [7] or Caltrans [8], do not fully address the modeling of this type of foundation system, e.g. no specific recommendation is proposed for modeling the soil-pile cap interaction, and (2) limited studies have been conducted on the seismic response of pile-supported bridge piers [1], [9], [10], [11]. The present study focuses on the model uncertainty in the numerical representation of bridge piers supported on pile foundations. For this purpose, the seismic behavior of a tall, partially-embedded, flared, reinforced-concrete pier supported on a pile foundation with a special configuration of its pile cap is parametrically investigated.

The SFS interaction can significantly affect the seismic response of bridges supported on soft soil. It may influence beneficially the seismic behavior of bridges by increasing their structural damping and decreasing the seismic forces [2]. On the other hand, it may be detrimental for bridges due to resonance, amplified P- $\Delta$ and pounding effects, that can cause overturning and unseating of the superstructure [12], [13]. It is well known that the SFS interaction may shift the fundamental frequency of the bridge closer to (farther from) the prevailing frequency of the seismic excitation, which causes increase (decrease) of the structural response [2]. Regarding P- $\Delta$ and pounding effects, the rocking movement of the pile cap due to the SFS interaction is especially important for tall bridges. It should also be noted that the bridge superstructure may be subjected to considerable torsional moment due to the foundation rotation about its vertical axis during earthquakes caused by: (1) seismic loading conditions, as, e.g., bilateral seismic loading, torsional components of earthquake motions [14], [15], and spatial variation of the ground motions [6], [15]; (2) foundation conditions, as, e.g., non-uniform properties of the soil surrounding the foundation, geometrical configuration of the foundation, and partial damage or failure of the foundation [16]; (3) structural configuration, as, e.g., when the mass center and the center of rigidity of the structural system do not coincide [14], and (4) collision of the bridge superstructure with 
abutments [17], [18] or adjacent spans [19]. Because of deck rotation about the vertical axis, the induced transverse movement may also lead to pounding and unseating of the superstructure.

The pile foundations may resist seismic forces with a combination of four components: (1) pilesoil-pile interaction; (2) passive earth pressure on the sides of the pile cap; (3) frictional forces at the base and sides of the pile cap, and (4) vertical resistance at the base of the pile cap. Various methods have been proposed for numerical modeling of the pile foundation [20] - [23]. Commonly, nonlinear $p-y, t-z$ and $Q-z$ curves are used to approximate the resistance of single piles buried in soil [24], and pile group effects are considered by various methods such as the p-multiplier method [25]. Even though there are many studies on the seismic behavior of single piles and pile groups, e.g. [3], [4] and [26] - [29], there are only few investigations related to the lateral and vertical behavior of the soil-pile cap system during seismic loading [30], [31]. In earthquake engineering applications, it is generally assumed that either the pile cap behaves like an equivalent thick pile or its resistance is conservatively ignored in pile foundation modeling. This lack of consideration of the pile cap contribution to the response may be partly due to the fact that the pile caps are usually located on the ground surface or very close to the ground surface and surrounded with soft soil. However, recent experimental investigations indicated that heavily buried pile caps may considerably contribute to the lateral resistance of pile foundations [22], [23].

There are six different aspects that may affect the numerical modeling of the SFS system in finiteelement analyses. These include: (1) structural modeling, such as mesoscopic or macroscopic finiteelement modeling approaches, and structural collapse criteria; (2) idealization of the mechanical behavior of structural materials, such as concrete and steel; (3) foundation modeling, such as direct or substructure (i.e., equivalent or Winkler springs) methods; (4) soil modeling and soil failure (or yield) criteria, such as, e.g., the Coulomb-Mohr criterion; (5) idealization of soil properties and soil profile, such as the variation of the cohesion, friction angle and lateral stress ratio of the soil with depth, and (6) boundary conditions, such as gaps between the ends of the bridge deck and the abutment, soil-foundation and soilabutment interface, and absorbing boundary conditions. The appropriate consideration of each one of these factors in modeling the SFS interaction is a challenging problem due to the uncertainties associated with the numerical representation of the system. Simplified models cannot accurately reproduce the actual nonlinear interaction of a SFS system due to increased model uncertainty, and sophisticated ones may result in an unreliable response due to increased parameter uncertainty [32]. Therefore, the best numerical representation of a SFS system is one that optimizes the incorporation of essential geotechnical and structural components in the finite-element model taking also into account their corresponding parameter uncertainty. 
In this paper, a detailed finite-element analysis on one of the piers of the Mogollon Rim Viaduct is performed by considering both geotechnical and structural modeling aspects of the SFS interaction to investigate the effect of the model uncertainty on the system response. The pier, a tall, partially embedded, flared, reinforced-concrete column, is modeled using three-dimensional, force-based, fibersection, beam-column elements [33]. The bond slip at the pier-pile cap connection as well as P- $\Delta$ effects are included in the structural modeling. The influence of two well-known confined concrete models, i.e., the Mander [34] and the Kent-Scott-Park [35], [36] concrete models, on the SFS system is studied. The soil-foundation interaction is modeled using $p-y, t-z$ and $Q-z$ nonlinear curves. The frictional resistance and passive earth pressure effects on the embedded part of the pier and the pile cap are considered. The significance of the natural slope of the ground surface on the lateral resistance of the pier and the capacity of the SFS system are investigated. The variations of the maximum moment and shear distribution along the pier and the pile foundation are examined. The effect of the loading patterns on the pushover response of the SFS system is also evaluated. Finally, the effect of the uncertainties in the specified vs. the actual compressive strength of the concrete on the pier response is investigated.

\section{Model description}

The Mogollon Rim Viaduct (built in 1991) is located on SR 260, which is the primary roadway between the rural towns of Payson and Heber in Central Arizona. It is a three-span bridge with total length of $277.36 \mathrm{~m}[910 \mathrm{ft}]$ (with spans of $85.34 \mathrm{~m}[280 \mathrm{ft}], 103.63 \mathrm{~m}[340 \mathrm{ft}]$ and $85.34 \mathrm{~m}[280 \mathrm{ft}]$ ) and width of $18.59 \mathrm{~m}[61 \mathrm{ft}]$ as shown in Fig. 1 (a). Since the maximum span of the bridge is longer than $90 \mathrm{~m}$, the bridge cannot be considered as "ordinary standard bridge" according to the Caltrans provisions [8]. The bridge superstructure is a precast, prestressed concrete, continuous girder, on a curve, with an uphill grade. The bridge has wing walls on the down-slope side of the two abutments, and extensive foundations for the two center piers, which are located on a natural slope.

The clear height of the bridge piers is $15.97 \mathrm{~m}$ [52.4 ft] and $20.79 \mathrm{~m}$ [68.2 ft] (first and second pier in Fig. 1 (a), respectively). The cross section of the piers changes with increasing height and has a flared shape. The base dimensions of the piers are $2.74 \mathrm{~m} \times 5.48 \mathrm{~m}[9 \mathrm{ft} \times 18 \mathrm{ft}]$ and their top dimensions $2.74 m \times 8.22 m[9 f t \times 27 f t]$. The first pier is rigidly connected to the superstructure, whereas the second, taller pier is seismically isolated from the deck with three elastomeric bearings (Fig. 1 (a)). The elastomeric pads have the same properties, which are: thickness $5.08 \mathrm{~cm} \mathrm{(2} \mathrm{in),} \mathrm{cross-sectional} \mathrm{area} 9000$ $\mathrm{cm}^{2}$, shear modulus $930 \mathrm{kN} / \mathrm{m}^{2}$, and lateral stiffness $167 \mathrm{kN} / \mathrm{cm}$. Because the Mogollon Rim Viaduct is a long-span bridge, the tributary dead load corresponding to each pier (Fig. 1(a)) is large (33361 $k N$ ). Hence, the total frictional resistance of these three elastomeric pads becomes large as well, and is 
evaluated by the product of the dynamic coefficient of friction between concrete and neoprene and the axial force of the pier due to the tributary dead load of the superstructure: $0.4 \times 33361 \mathrm{kN}=13344 \mathrm{kN}$. This frictional force is much greater than the total yield resistance of the elastomeric bearings, which is $7635 \mathrm{kN}$. Therefore, in this design, the three elastomeric bearings are not dissipative friction devices, but are just used to partially release the rotational constraints at the top of the second pier of the bridge.

The effective height of the first pier, i.e. distance from the mass center of the superstructure to the base of the pier, of the Mogollon Rim Viaduct is approximately $4.57 m$ taller than its clear height (15.97 $m$ ) and is equal to $20.54 \mathrm{~m}$. However, the effective and clear heights of the second pier of the Mogollon Rim Viaduct are the same and equal to $20.79 \mathrm{~m}$. In addition, the top of the first pier can be practically assumed as rotationally free [8] in its strong direction. Therefore, its behavior becomes very close to the second pier, which is seismically isolated along this direction, because both piers have approximately the same cross section, effective height and boundary conditions. For the aforementioned reasons, the response of the bridge along its transverse direction is not significantly affected by its irregular configuration and becomes relatively uniform under seismic excitations. In practice, such a design philosophy is called "partial isolation", and usually adopted to reach symmetry in the transverse direction of irregular bridges.

The pile caps consist of two parts, the super cap with horizontal dimensions of $5.48 \mathrm{~m} \times 5.48 \mathrm{~m}[18 \mathrm{ft}$ $\times 18 \mathrm{ft}]$ and depth of $2.28 \mathrm{~m}[7.5 \mathrm{ft}]$, and the sub cap with horizontal dimensions of $9.14 \mathrm{~m} \times 9.14 \mathrm{~m}[30 \mathrm{ft}$ $\times 30 f t]$ and depth of $2.28 \mathrm{~m}$ [7.5 ft]. The pile caps are supported on nine drilled shafts with diameter of $1.22 m[4 f t]$ as shown, for the second pier, in Fig. 1 (b). The soil profile, also illustrated in Fig. 1 (b), is based on the existing geotechnical information [37], and the soil properties are presented in Table 1. The natural slope of the ground surface is not shown in the soil profile of Fig. 1 (b); its effect, however, is examined in Section 4.

\section{Analysis framework and finite-element model}

The framework of the structural analysis of the SFS system is illustrated in Section 3.1. The pier and pile cap modeling procedures are explained in detail in Sections 3.2 and 3.3, respectively. Finally, the pile modeling is briefly illustrated in Section 3.4, as all aspects of this problem are well documented.

\subsection{Structural analysis approach}


The open-source software platform OpenSees of the Pacific Earthquake Engineering Research Center [38] is used for modeling the SFS system. Based on code recommendations, stand-alone analyses of structural components are utilized to estimate their nonlinear capacity [8]. Herein, the pushover method, as a capacity analysis tool, is implemented to examine the sensitivity of the nonlinear resistance of the bridge pier in the collapse prevention limit state to numerical modeling effects. The use of pushover analysis has three advantages: (1) simple physical interpretation of the numerical results; (2) clear identification of the nonlinearity (soil plasticity) and local failure mechanisms (bond slip) that may be developed and progress in the SFS system, and (3) separation of the effects of the input motion uncertainty from the finite-element model uncertainty. Because of the natural slope of the ground surface along the weak direction of the pier, pushover analyses are performed along its positive and negative weak directions (Fig. 1 (a)). In order to account for the effect of the superstructure weight on the pushover analysis, an axial compression force, equal to the tributary load of $33361 \mathrm{kN}$, is applied at the top of the pier.

For the lateral loading pattern of the pier, the effect of the higher modes is not considered in the distribution of the inertial forces due to the following three reasons: (1) for the second pier of the Mogollon Rim Viaduct, a plastic hinge can only form at the pier base, and higher modes cannot influence its location, (2) the contribution of higher modes to the inertial forces is small, because their effective modal mass ratios are small, e.g. for the strong (flared) direction of the second pier of the Mogollon Rim Viaduct, the contributions of the three first modes to the effective mass of the pier are: $0.8703,0.0802$, and 0.0240, and, for its weak direction: 0.8598, 0.0848, and 0.0276, and (3) after the formation of the plastic hinge at the pier base, the movement of the pier is fully controlled by its first mode shape if the effect of the elastomeric bearings at the top of the pier is ignored. Therefore, the optimal inertial loading pattern for this pier should be between a uniform and a triangular shape. Herein, as the worst-case scenario, the primary loading pattern for the pushover analysis is considered proportional to the nodal masses of the pier, but the effect of the two other loading patterns, i.e. triangular and first mode shape, on the response of the SFS system is also examined.

\subsection{Pier modeling}

The seismically isolated pier (Fig. 1 (b)) is modeled as a cantilever column using three-dimensional fibersection, force-based, beam-column elements [33]. The pier is flared in its strong direction and therefore, six different sections are introduced based on the variations of the arrangement of the longitudinal reinforcing steel (Figs. 1 (b) and 2). It is assumed that the unconfined concrete is not very influential on the moment-curvature diagrams. It should be noted that the definition of the concrete confinement outside 
the column core in flared piers can be very complicated. For the pier considered herein, categorizing concrete into confined and unconfined is quite uncertain (see, e.g., Section A-A in Fig. 1 (b)). Therefore, only the concrete cover is considered as unconfined. The concrete between the concrete cover (unconfined concrete) and the core concrete (confined concrete) in the flared part (Section A-A in Fig. 1 (b)) may be characterized as low confined concrete. Its behavior falls in-between that of confined and unconfined concrete depending on the area ratio and the configuration of the transverse reinforcement.

The expected material properties of the modeled members are used herein, since the goal of the study is to capture the actual behavior of the system [8]. A uniaxial bilinear steel material with kinematic hardening and expected material properties as given in Caltrans for steel grade 60 [8] is used to model the reinforcing steel. In seismic bridge response evaluations, either the uniaxial Mander or the uniaxial KentScott-Park concrete materials with degrading linear unloading/reloading stiffness [39] and no tensile strength are commonly used to model the pier and foundation concrete. Mander's concrete model is applicable to all section shapes and all levels of confinement in all strain-rate loading conditions, even though the use of this model for high-strain rate loading conditions appears to be un-conservative [40], [41]. Mander's concrete model is commonly recommended by codes to model the confined concrete behavior for quasi-static loading conditions [8]. The Kent-Scott-Park concrete model is applicable to rectangular shaped sections and all levels of confinement for both low- and high-strain loading conditions [36]. For seismic excitations, the consideration of the cross section of the pier (Fig. 1 (b)) implies that the Kent-Scott-Park concrete model with high-strain rate may be a better choice for estimating the actual response of the reinforced concrete pier. Both concrete models, i.e. Mander's low-strain rate concrete model and the Kent-Scott-Park high-strain rate concrete model, are used in this study to compare the effect of the selection of the concrete constitutive models on the structural response. For the Kent-ScottPark concrete material, the maximum expected compressive stress and strain are $45677 \mathrm{kN} / \mathrm{m}^{2}$ and 0.00265, respectively, and the ultimate expected compression stress and strain $9135 \mathrm{kN} / \mathrm{m}^{2}$ and 0.021 , respectively. For Mander's concrete material, the maximum expected compressive stress and strain, are $41368 \mathrm{kN} / \mathrm{m}^{2}$ and 0.004, respectively, and the ultimate expected compression stress and strain 24752 $\mathrm{kN} / \mathrm{m}^{2}$ and 0.021 , respectively. With the consideration of environmental effects on the concrete cover strength, the unconfined concrete is modeled in the same manner for both confined concrete behaviors with the maximum expected compressive stress and strain being equal to $34473 \mathrm{kN} / \mathrm{m}^{2}$ and 0.002 , respectively, and a spalling strain of 0.005 according to the Caltrans provisions [8].

A sensitivity analysis was performed to determine the optimal number of fibers of the most complicated Section 6 of the pier (Fig. 2). This was achieved by increasing the number of fibers until the differences between the moment-curvature diagrams of the section modeled with two consecutive 
numbers of fibers were minimal. The analysis led to 432 concrete and 140 steel fibers. Herein, all sections contain 432 concrete fibers and the number of steel fibers was determined from the different reinforcement characteristics of the sections: Sections 1 and 2 have 76 steel fibers, Section 3 has 92, Section 4 has 108, Section 5 has 124, and Section 6, as noted above, has 140 steel fibers (Table 2). With the consideration of the stiffness and mass distribution, and the longitudinal reinforcing arrangement along the flared pier, eight elements are used to model the pier and three or five integration points, as provided in Table 2, are considered for each element. A sensitivity analysis was performed to verify the objectivity of the local and global response of the model, and no numerical convergence problems were observed by varying the number of integration points. The strain localization of the force-based elements is not an issue for this system, because the axial load ratio of the pier is less than $10 \%$ (Table 2), and its pushover response shows a mild strain hardening behavior, as discussed in Section 4. It is further noted that the length of the first integration point of the first pier element is considered to be less than the empirical plastic hinge length of the pier.

The pier is partially embedded in soil consisting of two different layers: loose sand with $1.52 \mathrm{~m}$ depth and medium sand with $3.04 \mathrm{~m}$ depth. To account for the effect of soil embedment on the behavior of the pier, it is assumed that the pier acts as a cantilever retaining wall. The dynamic passive earth pressure and frictional forces against the pier movement may be estimated by one of the methods discussed in the subsequent Section 3.2 with the assumption of plane strain conditions. The underestimation of the soil resistance due to the plane strain assumption is modified by considering a correction factor for three-dimensional effects [42]. The equivalent nonlinear $p-y$ and $t-z$ springs are attached to the model using rigid links at nodes 2 and 3 (Figs. 1 (b) and 2).

The bond-slip effect is modeled based on the method discussed in Ref. [43]. In this approach, a duplicate node is placed between the pier and the pile cap to connect them with a zero-length section element. The section configuration of the zero-length element is the same as the pier section, but the hysteretic behavior of its reinforcing steel is modified so as to include bond-slip effects. The torsional and two in-plane horizontal degrees of freedom of the added node are constrained to its adjacent node to prevent sliding of the beam-column element under lateral loading, since torsional and shear resistance is not included in the zero-length section element. Herein, the rebar slippage at the pier-pile cap interface is considered as $0.208 \mathrm{~cm}$ and $7.290 \mathrm{~cm}$ corresponding to the yield and fracture strength of the bar, respectively [43]. This consideration of the large rebar slippage is due to the use of the bundled longitudinal bars in the reinforced-concrete section of the pier (Fig. 1(b)), which make the pier vulnerable to bond-slip effects. A single equivalent bar with the same area of the 2 bar bundle (with size \#11) is used in the bond slip modeling (Fig. 1(c)). This modeling scenario may underestimate the bond strength of the 
actual pier because the perimeter of the single equivalent bar is less than the effective perimeter of the 2 bar bundle with the two probable bond failure mechanisms as shown in Fig. 1(c), and therefore, may be considered as the worst case scenario. In addition, because of the possibility of the poor construction of bundled bars and formation of weakened concrete between them, as well as the unsatisfactory configuration of the hoops and the cross ties (Sections A-A and B-B in Fig. 1 (b)), the considered bond slip modeling scenario may be justified as a conservative approach.

The second order P- $\Delta$ effect is also included in the analysis of the pier. The use of either one of the transformation methods included in OpenSees, i.e. P-Delta and corotational transformation, does not result in any significant differences for the seismically isolated pier, because of its low axial load ratio (Table 2). The corotational transformation, as the more accurate approach, is used to incorporate the effects of both P-big delta $(\Delta)$ and P-small delta $(\delta)$ in the following. In addition, linear transformation is assumed for the pile foundation modeling.

For a pushover analysis, it is required that a specific target ductility demand, $\mu_{\Delta}$, for the pier be estimated. According to Caltrans [8], the target ductility demand in both strong and weak direction of the pier (Fig. 1) of the Mogollon Rim Viaduct should be $\mu_{\Delta} \leq 4$. However, the pier system should be considered as a limited ductility structure [44] with $\mu_{\Delta} \leq 3$ because of two main reasons, namely the pier embedment and the configuration of the transverse reinforcement in the reinforced concrete section. The pier embedment causes the plastic hinge to occur below the ground level, which results in difficulty of damage inspection after a strong ground motion. In addition, large yielding of the pier below ground level may lead to an unacceptable level of residual displacement [45]. Regarding the transverse reinforcement of the pier (Sections A-A and B-B in Fig. 1 (b)), the unsatisfactory configuration of the hoops (consisting of tie anchorages with $90^{\circ}$ overlapping hooks at corners) and the cross ties (spliced in the compression core) restrict the ductility capacity of the reinforced concrete section [46]. Thus, not only the concrete core is not effectively confined by the transverse reinforcement, but, also, bar buckling may occur after the concrete cover spalls. Therefore, the ductility of the pier is estimated with the assumption of a spalling limit state as the concrete cover spalls.

The moment-curvature diagrams are usually evaluated assuming an axial compression load equal to $1 \pm 0.5 k_{h}$ times the superstructure dead load, with $k_{h}$ being the ratio of the peak ground acceleration (PGA) of the horizontal earthquake components to the gravitational acceleration $(g)$ [47]. Herein, only the superstructure load is considered because the effect of the axial force variations on the flexural strength and ductility of the reinforced concrete sections can be clearly determined [48]. Fig. 3 presents the moment-curvature diagrams corresponding to the different sections of the pier using the Kent-Scott-Park 
and Mander models in parts (a) and (b), respectively. The properties of the pier sections, i.e. the yield curvature $\left(\phi_{y}\right)$, the ultimate curvature $\left(\phi_{u}\right)$, the inelastic rotational ductility capacity $\left(\mu_{\phi}=\phi_{u} / \phi_{y}\right)$, and the ratio of the ultimate moment capacity $\left(M_{u}\right)$ to the yield moment capacity $\left(M_{y}\right)$ are presented in Table 3. As can be seen in Fig. 3, the moment capacity of the sections increases with increasing section number, i.e. the first section has the lowest moment capacity and the sixth section the highest. This variation is not so significant for the capacity of the pier along its weak direction, but becomes quite substantial along its strong direction due to the fact that the increase of the dimension of the pier cross section with height occurs along this latter direction. Three observations can be made from the comparison of the moment curvature of the different sections of the pier. First, it is generally considered that the yield curvature is inversely proportional to the effective depth of the reinforced concrete section [48]. Such a specific trend is not apparent for the pier sections in Fig. 3 and Table 3. The lack of such a trend may be justifiable, because of the configuration of the longitudinal reinforcement and the variation of the reinforcement area ratio in the different sections of the flared part of the pier. Second, the ultimate curvature decreases with increasing section number (cross section dimension) in the strong direction, whereas the opposite occurs in the weak direction. An exception occurs for the second section of the pier for both concrete constitutive models along the strong direction, the reason being that the thickness of the concrete cover in the strong direction of this section is larger than that of the other sections. The higher ultimate curvature of the first section in comparison to those of sections 3-6 along the strong direction suggests that this behavior may be mostly caused by the overall higher compression steel content in this section, i.e. the decrease of the compression steel content will lead to the decrease of the ultimate curvature and vice versa [48]. Third, the yield curvature and ultimate curvature of the sections modeled with the Kent-Scott-Park confined concrete material are, generally, smaller and larger, respectively, than those of the corresponding sections modeled with Mander's confined concrete material (Fig. 3 and Table 3). As a consequence, the sections modeled with the Kent-Scott-Park concrete material have larger rotational ductility capacity. This may be attributed to the difference in the strength of the confined concrete corresponding to these two material models. As a general rule, the increase of the concrete strength increases section ductility [48], and, therefore, sections modeled with the Kent-Scott-Park concrete material are more ductile than those modeled with Mander's approach in the spalling limit state (Table 3).

Considering that the ultimate curvature corresponds to the state that the concrete cover spalls, the target displacement ductility of the pier along both its directions may be approximated by [47]:

$\mu_{\Delta}=\frac{M_{u}}{M_{n}}+3 \frac{l_{p}\left(l-0.5 l_{p}\right)}{l^{2}}\left(\frac{\phi_{u}}{\phi_{y}}-1\right)$ 
where $M_{n}$ is the nominal moment capacity, $l$ is the distance from the point of maximum moment to the point of contra-flexure $(l=20.79 \mathrm{~m})$, and $l_{p}$ is the plastic hinge length evaluated as $2.04 \mathrm{~m}$ according to the Caltrans provision [8]:

$l_{P}=0.08 l+0.022 f_{y e} d_{b l} \geq 0.044 f_{y e} d_{b l}$

where $f_{y e}$ is the expected yield tensile strength of the steel (in Mpa) and $d_{b l}$ is the diameter of the longitudinal reinforcement bars (in $\mathrm{mm}$ ). The second term on the right-hand side of the equality in Eq. 2 results from the contribution of the bond-slip effect, and its significance to the response of this flared pier is examined in Section 4. Considering Eq. 1 and Table 3, the inelastic ductility capacity of the pier along its weak and strong directions, respectively, become $\mu_{\Delta}=2.21$ and 3.04 for Mander's concrete model, and $\mu_{\Delta}=2.79$ and 3.67 for the Kent-Scott-Park concrete model. To satisfy the condition of $\mu_{\Delta} \leq 3$, the maximum displacement at the top of the pier to be used in the pushover analysis is estimated assuming a ductility capacity consistent with the results of Mander's concrete model as follows [8], [44]:

$\Delta_{\max }=1.5 \Delta_{c}=1.5 \mu_{\Delta} \Delta_{y}^{\text {pier }}=1.5 \mu_{\Delta} \frac{l^{2} \phi_{y}}{3}=\left\{\begin{array}{l}3.04 \times \frac{(20.79 \mathrm{~m})^{2} \times\left(0.728 \times 10^{-3} / \mathrm{m}\right)}{2}=47.83 \mathrm{~cm} \text { (Strong Direction) } \\ 2.21 \times \frac{(20.79 \mathrm{~m})^{2} \times\left(1.42 \times 10^{-3} / \mathrm{m}\right)}{2}=67.87 \mathrm{~cm} \text { (Weak Direction) }\end{array}\right.$

where $\Delta_{c}$ is the displacement capacity, and $\Delta_{y}^{\text {pier }}$ is the idealized yield displacement of the pier at the formation of the plastic hinge. Eq. 3 considers that the base of the pier is fixed. For a specific target displacement capacity, larger displacements should be applied at the top of the pier if the foundation flexibility is considered; this point is further discussed in Section 4.

\subsection{Pile cap modeling}

Past research on the lateral resistance of pile caps indicated that they can considerably increase the stiffness of the pile foundations [22], [23]. The pile caps of the piers of the Mogollon Rim Viaduct consist of the super cap and the sub cap, both fully embedded in the soil (Fig. 1). Elastic beam-column elements are used to model the pile cap with the consideration of cracked concrete section. Because the pile foundation is surrounded by competent soil, equivalent nonlinear $p-y$ and $t-z$ springs are introduced for the soil-pile cap interaction as illustrated in the following subsections. It is iterated that the same formulation of the $p-y$ and $t-z$ curves is utilized for the embedded part of the pier (Section 3.1 and Fig. 2).

\subsection{1. $\quad p-y$ springs}


The nonlinear $p-y$ curves for modeling the soil-pile cap interaction are estimated using a hyperbolic equation of the form [31]:

$$
P=\frac{y}{\frac{1}{k_{\max }}+R_{f} \frac{y}{P_{u l t}}}
$$

where $P$ is the load at deflection $y, P_{u l t}$ is the ultimate passive force, $k_{\max }$ is the initial stiffness obtained herein with the approach provided in Ref. [49], and $R_{f}$ is the failure ratio. The current practice for the seismic design of retaining walls is based on the Mononobe-Okabe (M-O) method [24]. This method is a straight forward extension of the Coulomb sliding wedge theory to estimate the ultimate passive force on retaining walls. The seismic effects are considered by introducing vertical and horizontal coefficients of acceleration, $k_{v}$ and $k_{h}$, induced by an earthquake ( $k_{v}$ is the ratio of the PGA of the vertical earthquake component to the gravitational acceleration). It is recommended that $k_{h}=0.5 \mathrm{PGA} / g$ in the M-O method is an adequate value for limit equilibrium pseudo-static design, provided allowance be made for a lateral wall movement of 25.4 PGA $/ \mathrm{g}(\mathrm{cm})$ [50]. Although the M-O method is commonly applied to cohesionless soils, it can be modified to be applied to soils with cohesion as well [51].

Other approaches for the estimation of $P_{u l t}$ have also been presented and include: (1) the classical methods based on a planar sliding surface, such as the Coulomb and Rankine methods as well as the aforementioned M-O approach; (2) more recent methods based on a curved failure surface, such as the log spiral method [52], and the method of slices [53], [54], and (3) procedures based on the lower bound theorem of the theory of plasticity [55]. In spite of the fact that the more recent methods provide more realistic values of $P_{u l t}$ as compared to experimental data [23], the M-O method is still applied for the estimation of the dynamic passive earth pressure in seismic design [24]. This is mostly due to the fact that the M-O method is a closed form approach with simple assumptions, and partly due to the uncertainties of the soil properties in engineering applications.

Fig. 4 illustrates the variation of $p-y$ curves evaluated based on four different methods: Coulomb, log spiral, M-O and Rankine. As can be seen from the figure, the Rankine method provides the lowest resistance for the passive earth pressure, since it assumes no friction at the wall-soil interface. The Coulomb method, which is the general version of the Rankine method, provides the largest resistance for the passive earth pressure. The log spiral method, which considers a logarithmic spiral surface for the rupture and is consistent with experimental results, provides lower resistance than the M-O and Coulomb methods, which consider a planar sliding surface. The M-O method results fall in-between the Coulomb and log spiral methods. 
Two approaches are utilized in the present sensitivity analysis: the log spiral method (that reflects a more accurate approach) and the $\mathrm{M}-\mathrm{O}$ method (that represents the current design approach). In the evaluation of the values of $P_{u l t}$ for the super and sub caps, it is considered, for both methods, that $k_{h}=0.2$ and $k_{v}=0.13$, which correspond to an assumed earthquake with PGA of $0.4 g$ for the horizontal component. In addition, the angle of friction between the pile cap and the soil, $\delta$, is considered as $\delta=2 \phi / 3$ [56] and $\delta=3 \phi / 4$ [57] for the log spiral and the M-O methods, respectively. It should be mentioned that larger values of $\delta$ may occur in-situ due to the restrained vertical movement of the pile cap, which is caused by the pile group [58]. The other estimated values of the parameters in Eq. 4 are provided in Table 4. The effect of the application of these two methods on the structural response of the pier is presented in Section 4. Clearly, as Fig. 4 suggests, the code recommended M-O method leads to a stiffer SFS system in comparison to the one resulting from the more realistic log spiral approach.

Using Eq. 4, nonlinear $p$ - $y$ curves are introduced in OpenSees to model the lateral resistance of the pile cap due to the passive earth pressure. In the application of Eq. 4, the most important factor after the estimation of the ultimate passive force is the location of the $p-y$ spring in the finite-element model. For passive earth pressure, the static resultant force, $P_{u l t}$, is commonly placed at the lower one-third of pile cap height $\left(H_{p c}\right)$ with the assumption of a triangular pressure diagram; however, some evidence suggests that the location of the static resultant force may be placed at the middle one-third of the pile cap height [59]. This is definitely not the case for dynamic forces [60]. In fact, based on the movement of the system during an earthquake, the location of the resultant force may vary. To address this issue, it was assumed that the point of application of the resultant force was located in the middle one-third of the pile cap height, and a sensitivity analysis was performed on the model with the equivalent nonlinear $p-y$ springs placed at $0.4,0.5$ and $0.6 H_{p c}$. It was determined that the consideration of the center of each pile cap part as the point of application of the resultant passive force does not significantly affect the response, and, hence, can be justified as an acceptable assumption. It is obvious that the estimation of the exact location of the point of application of the resultant passive force is still questionable due to the uncertainties related to the dynamic behavior/characteristics of the soil.

\subsection{2. $t-z$ springs}

To model the frictional forces at the horizontal and vertical surfaces of the pile cap in a SFS interaction system (Fig. 5 (a)), the ultimate frictional capacity, $t_{u l t}$, and the displacements at which $50 \%$ of $t_{u l t}$ is mobilized in monotonic loading, $y_{50}$ or $z_{50}$, should be determined (Fig. 5 (b)). For piles buried in cohesionless soils, API recommends that the value of $y_{50}$ or $z_{50}$ be considered as $0.127 \mathrm{~cm}$ [61], and experimental results show that this value may be assumed in the range of $0.254 \mathrm{~cm}$ to $0.635 \mathrm{~cm}$ [28]. 
Herein, it is conservatively considered that this value is $0.508 \mathrm{~cm}$ for all frictional force types because of the larger dimensions of the pile caps in comparison to the piles [10]. The ultimate frictional capacity on the horizontal and vertical surfaces of the pile cap is estimated as described in the following.

\subsubsection{Horizontal surface friction}

The ultimate surface friction forces on the horizontal surfaces of the pile cap may be obtained using the Coulomb-Mohr (C-M) criterion for cohesionless soils [62]. Using this approach, the ultimate horizontal surface friction forces are estimated by:

$t_{\text {ult }}^{\text {hor }}=\left(1 \pm k_{v}\right)\left[\sigma_{z} A_{\text {eff }}+\alpha N\right] \tan (\delta) \quad$ where $\quad \begin{cases}0 \leq \alpha<1 & \text { at the base of the pile cap } \\ \alpha=0 & \text { elsewhere }\end{cases}$

where $\sigma_{z}=\gamma z$ is the vertical effective stress of the soil at depth $z, \gamma$ is the dry unit weight of soil, $A_{\text {eff }}$ is the effective area of the pile cap in contact with the soil, $N$ is the axial load due to the bridge weight supported by the pile foundation, and $\alpha$ represents the contribution of the base of the pile cap to the vertical bearing capacity of the pile foundation. The first term on the right-hand side of Eq. $5,\left(1 \pm k_{v}\right)$, represents the effect of the vertical component of the earthquake on the horizontal surface frictional forces. It should be noted that the horizontal component of the earthquake does not directly affect the frictional capacity of the pile cap according to Eq. 5, but it may reduce the friction angle between the concrete and the soil [56]. Based on the recommendation of IBC [63], it is assumed in the present study that the soil below the pile cap does not carry any vertical load $(\alpha=0)$. Three effective areas, $A_{\text {eff, }}$ are considered for the loading along the strong direction of the pier as illustrated in Fig. 5 (c); a similar pattern is used for the loading along the weak direction of the pier. The effective areas should be compatible with the assumptions used in Section 3.2.1 in defining $P_{u l t}$. For example, for both soil constitutive models used herein, it is assumed that the soil behind the pile cap behaves as a rigid body and moves with the pile cap. Therefore, as shown, e.g., in the middle part of Fig. 5 (c) for the horizontal surface of the top part of the sub pile cap, the contribution of the soil to the frictional forces behind the super cap should be removed, and, consequently, the effective area should be reduced. The values of $t_{u l t}^{\text {hor }}$ for the base, middle and top horizontal surfaces of the pile cap (Fig. 5 (c)) are presented in Table 4.

\subsubsection{Vertical surface friction}


The ultimate friction force on the vertical surfaces of the pile cap (pile cap sides) is also obtained using the $\mathrm{C}-\mathrm{M}$ criterion as:

$$
t_{u l t}^{v e r}=b \int_{z_{1}}^{z_{2}} K \sigma_{z} \tan (\delta) d z
$$

where $b$ is the width of the pile cap ( $b=9.14 \mathrm{~m}$ for the sub cap and $5.48 \mathrm{~m}$ for the super cap), and $K$ is the coefficient of lateral earth pressure. The value of $K$ is estimated based on the pile cap movement, i.e. active, at rest, and passive earth pressure conditions. The effect of the earthquake components on the vertical surface friction forces can be directly considered in the estimation of $K$ [53], [54]. In addition, the seismic loading condition will affect the value of the interface friction angle between the concrete and the soil [56]. According to the API recommendations, the value of $K$ for piles should be in the range of 0.8 to 1 [61], but this does not appear to be a realistic assumption for pile cap modeling. High values of $K$ in the top $9.14 \mathrm{~m}$ of the surface layer have been reported for both cohesion soils due to high overconsolidation ratios [53], and cohesionless soils due to dilation [26]. Herein, to evaluate the integration of Eq. 6, it is assumed that [26]:

$$
K=4.62 \exp [-0.137 z]
$$

where $z$ is in $m$. With the consideration of $\sigma_{z}=\gamma z$, one can easily obtain:

$$
t_{u l t}^{v e r}=-4.62 b \gamma \tan (\delta)\left[\frac{z \exp [-0.137 z]}{0.137}+\frac{\exp [-0.137 z]}{(0.137)^{2}}\right]_{z_{1}}^{z_{2}}
$$

The $t-z$ springs corresponding to the horizontal and vertical surface frictional forces are attached to the model with rigid links at the centers of the eight sides and the bases of the pile cap (Fig. 5 (a)) as shown in Fig. 2. Because of the symmetry of the pile cap, only the values of the $t$ - $z$ springs of two vertical surfaces are provided in Table 4.

\subsection{Pile modeling}

The pile foundation consists of nine circular drilled shafts with diameter of $1.22 \mathrm{~m}$ and total length of $28.04 \mathrm{~m}$. The geometric configuration of the shafts and the pile cap is presented in Figs. 1 (b), 2 and 5 (a). The cross section of each pile is modeled using three-dimensional fiber section, force-based, beamcolumn elements to consider the flexural failure mechanism corresponding to the occurrence of plastic hinges within piles. Mander's concrete model and uniaxial bilinear steel with expected properties are applied in the fiber section modeling. The nonlinear $p-y, t-z$ and $Q-z$ springs with the hysteretic behavior 
discussed in Refs. [20], [27], [28], [61] are used to represent the soil-pile interaction. However, even though the pile-to-pile and soil-to-soil interaction effects [64] are not directly considered in formulation of $p-y, t-z$ and $Q-z$ curves, the accuracy of the nonlinear springs has been verified in experimental analyses [20]. The $p-y$ springs are closely spaced along the active length of the pile [29]. The same approach is used in placing the $t-z$ springs along the pile axis for modeling the skin frictional forces. A single $Q-z$ spring is placed at the tip of each pile to reflect its end bearing capacity.

In a pile group, interaction between the piles may reduce the bearing capacity of each pile, if the pile spacing is less than six times the pile diameter for cohesionless soils [7]. Herein, the pile group effects are considered in the pile modeling as the pile spacing is three times the pile diameter. Because the soil surrounding the piles of the viaduct is approximately of the same type (cohesionless soil-very dense sand), the individual capacity of each shaft is reduced by a group efficiency factor of 0.7 [7], i.e. the ultimate strength of both $p-y$ and $t-z$ springs is multiplied by 0.7. It is noted that there are alternative approaches to consider pile group effects, as, e.g., the p-multiplier method [25], which is based on the application of different reduction factors to piles in leading and trailing rows, and to corner piles. Clearly, the definition of the leading and trailing rows depends on the loading direction, and the use of the pmultiplier method is only justified in monotonic loading conditions and not dynamic ones. In addition, this method is only applicable to $p-y$ curves and not $t-z$ curves. Because the seismic response of tall piers is mostly controlled by their flexural resistance and the rotational capacity of the pile group mainly depends on the skin frictional resistance of the piles ( $t-z$ curves), the uniform group efficiency reduction is utilized herein to have a consistent approach for both $p-y$ and $t-z$ curves. In addition, it should be mentioned that the numerical results of the sensitivity analysis conducted in the next section show that the contribution of the pile group to the lateral resistance of the pile foundation is not comparable to that of the pile cap and, therefore, the pile group effect is not an influential factor.

\section{Numerical results}

In this section, the effect of the model uncertainty in the numerical representation of the SFS system on its pushover response is assessed using the nine models highlighted in Table 5. The results of these comparisons are plotted in Figs. 6 to 11. All contributing structural and geotechnical components and effects are included in Model A (general model). Model A includes P- $\Delta$ and bond-slip effects, the effects of pier and pile embedment, and pile-to-soil interaction. Models B, C and D are fixed at the base; fixity is defined at the top of the pile cap and corresponds to the location of node 1 (Figs. 1 (b) and 2). The P- $\Delta$ effect is included in Model B, both P- $\Delta$ and bond-slip effects are considered for Model C, and all structural and geotechnical considerations up to the bottom of the pier are included in Model D (i.e. P- $\Delta$ 
and bond-slip effects, and partial embedment of the pier). Models E-I release the assumption of fixed base and consider pile-to-soil interaction. Models E and F include full SFS interaction effects, but Model E considers bond-slip and no P- $\Delta$ effects, whereas Model F considers P- $\Delta$ and no bond-slip effects. Models G-I contain the structural (bond-slip and P- $\Delta$ ) effects and various aspects of the geotechnical considerations. Model $\mathrm{G}$ does not incorporate the effect of the partial embedment of the pier. Model $\mathrm{H}$ does not include the effects of the partial embedment of the pier and the pile cap resistance; notably, Model H constitutes the most "conventional" model used herein regarding geotechnical considerations, i.e. it incorporates only the pile-to-soil interaction effects in the SFS system. It is emphasized that, whereas this model may be applicable to bridges with pile caps located on or very close to the ground surface, it cannot reproduce the contribution of heavily buried pile caps to the response [22], [23], as will also be illustrated in the following. Finally, Model I does not contain the effects of frictional forces on the embedded part of the pier and the pile cap.

The comparison of the results presented herein is based on the variation of the shear force, $F$, at the three nodes 1 (top of pile cap), 2 (middle of second soil layer), and 3 (middle of the ground surface soil layer) along the pier (Figs. 1 (b) and 2) with the top lateral displacement of node 9, $\Delta$, (Fig. 2). As illustrated in Fig. 1 (a), the ground surface is flat at the left-hand side and steep at the right-hand side of the pier. To investigate the effect of the ground surface slope on the pier response, the negative weak direction (flat ground surface) of the pier is considered first in the pushover analysis, and the investigation of the slope effect in its positive weak direction is subsequently evaluated.

Fig. 6 compares the effect of the two concrete constitutive models on the response of Model C along its strong and negative weak directions due to pushover. Model C (Table 5) is structurally "complete", as it incorporates both bond-slip and P- $\Delta$ effects, but its base is fixed, so that its response is not affected by the SFS interaction. Fig. 6 indicates that there is a significant difference between the responses of the system modeled with the two concrete materials, more so along its strong than its weak direction. The bond-slip effect causes a mild drop in the shear forces at all nodes of the system modeled with the Kent-Scott-Park material when the top lateral displacement approximately reaches the idealized yield displacement of the pier, i.e. $8.18 \mathrm{~cm}$ and $17.37 \mathrm{~cm}$ along the strong and weak direction of the pier, respectively. This behavior suggests that the maximum contribution of the bond slip to the flexural displacement occurs at the yield displacement of the pier, an observation that is in agreement with existing experimental results [43]. The difference in the response behavior of the system may be attributed to the gradient of the strain distribution across the cracked cross section of the pier caused by the two concrete models. The compression strength of the concrete model corresponding to the KentScott-Park concrete at low strains is larger than Mander's model. Therefore, the depth of the neutral axis 
corresponding to the Kent-Scott-Park concrete model is shorter than that of Mander's model, and, hence, the distance of the extreme row of the tension steel from the neutral axis increases. This behavior also resulted in the lower values of the yield curvature for the Kent-Scott-Park concrete model (Table 3 and Fig. 3). The variation in the location of the neutral axis of the section from the use of the two different concrete models leads to the steeper gradient of strain distribution for the Kent-Scott-Park concrete model. Because the effective depth of the tension steel is longer along the strong direction (Fig. 1 (b)), the bond slip is more significant along this direction and is more strongly influenced by the characteristics of the concrete constitutive model.

It is commonly assumed that the bond resistance between concrete and steel mostly controls the bond-slip behavior of reinforced concrete sections. The observations from Fig. 6, however, indicate that the concrete compression strength is also an influential factor, and are in agreement with experimental results [65]. The results of Section 3.1 and the ones presented in Fig. 6 suggest that the use of Mander's concrete model for the estimation of the rotational ductility capacity of a rectangular section may be a conservative approach, but the use of this same concrete model for the estimation of the bond-slip effect may be un-conservative. It should also be noted that, if the enhancement of the confined concrete strength with age [47] and the deterioration of the unconfined concrete strength with age [66] are considered in the concrete models, the bond-slip effects may become more significant, an observation that is particularly important for the seismic assessment of old tall bridges. Finally, it should be noted that the pier satisfies Caltrans' criterion of minimum lateral strength in its weak and strong directions for both concrete models. The criterion requires that the ratio of the minimum lateral strength of the pier over the corresponding tributary dead load of the superstructure be greater than 0.1. From Fig. 6 and with the consideration that the tributary dead load of the superstructure is $33361 \mathrm{kN}$, this ratio is 0.29 and 0.46 for Mander's concrete model, and 0.28 and 0.27 for the Kent-Scott-Park concrete model in the pier's weak and strong direction, respectively. For the aforementioned reasons, the Kent-Scott-Park concrete material model is used in the subsequent evaluations.

Fig. 7 presents the numerical results for the strong direction of the pier considering the nine different models for the SFS interaction system (Table 5); the M-O method with $\delta=3 \phi / 4$ was assumed for the soil-foundation modeling (design-based approach). All subfigures present the variation of shear forces at nodes 1, 2 and 3 with the displacement $\Delta$ at node 9, i.e., the top of the pier (Figs. 1 (b) and 2). Fig. 7 (a) shows the pushover results for the general Model A, which includes all SFS considerations and forms the basis of the comparison with the results of the other, more simplified models (Figs. 7 (b) to (i), and Table 5). Fig. 7 (c) is identical to the left part of Fig. 6 (a) discussed earlier. First, it is noted that all models that do not consider the pier embedment effect (Models B, C, G and H in Table 5) result in shear 
forces at node 1 that are higher than those at node 2, which, in turn, are higher than those at node 3 (Figs. 7 (b), (c), (g) and (h)). A similar behavior of shear forces can be observed at low displacement values for Model D (Fig. 7 (d)) before bond slip occurs, i.e., forces are higher for decreasing node number. After bond slip occurs in Model $\mathrm{D}$, there is a decrease in the shear forces at node 1 relative to the forces at the other two nodes. This behavior may be attributed to the fact that, at small displacements, the fixed base condition at the support causes a shear force behavior similar to that of the fixed base of Model C (Fig. 7 (c)), but, after bond slip, the pier embedment resistance picks up causing the decrease of the shear force at the lowest node. The comparison of Models B and C (Figs. 7 (b) and (c)) clearly illustrates the bond-slip effect. Both models are fixed at the base, but Model C includes bond-slip and P- $\Delta$ effects, whereas Model B reflects only the P- $\Delta$ effect contribution. Clearly, the bond slip causes a localized failure (Fig. 7 (c)), and neglecting its effect leads to a completely different distribution of shear forces along the pier (Fig. 7 (b)). The flexibility of the SFS system has the additional effect of shifting this localized damage to higher displacements (Figs. 7 (a) and (e) in comparison to Figs. 7 (c) and (d)). Interestingly, P- $\Delta$ effects are not so important for the strong direction of the pier, in the sense that P- $\Delta$ effects are not, at any level, comparable with the bond-slip effects: Models A and E are identical (Table 5), except that the former includes P- $\Delta$ effects whereas the latter does not. Shear forces in these two models (Figs. 7 (a) and (e)) do not vary significantly, indicating that the bond slip prevents the pier from reaching its maximum ductility capacity, and, hence, reduces the P- $\Delta$ effects on the pier. (Parenthetically, it should be noted that this is certainly not the case for the global bridge system). The comparison of the results of Models B and F, which do not consider bond-slip effects, but the former is fixed at the base whereas the latter considers SFS interaction (Table 5), points to the significance of the foundation flexibility, as the fixed model at the base (Fig. 7 (b)) significantly overestimates the shear forces of the more realistic flexible model (Fig. 7 (f)). Figs. 7 (g) - (i) indicate that neglecting considerations such as the pier embedment, the pile cap resistance and frictional forces in the embedded pier and the pile cap can considerably change the force variations along the pier. Fig. 7 (h) suggests that the pier embedment and the pile cap resistance are most important parameters, as the response of Model H (Fig. 7 (h)) is not comparable with the response of the realistic Model A (Fig. 7 (a)). Model H becomes unstable and a global failure or full collapse occurs at a displacement of $42.87 \mathrm{~cm}$, i.e. the structure cannot resist against further lateral loading and the pier will overturn. Such a behavior may be justified due to the height of the pier, since a small rotation at the foundation level can cause a large displacement at the top of the pier. Furthermore, the comparison of Figs. 7 (h) and (i) indicates that the incorporation of passive earth pressure effects on the partially embedded pier and pile cap, included in Model I but not in Model H (Table 5), can significantly affect the structural response. It is worth noting that the maximum and minimum shear forces occur for Model B (fixed base condition) and Model H (most flexible base condition), respectively. 
Fig. 8 presents the numerical results corresponding to those of Fig. 7 but for the negative weak direction of the pier. As in Fig. 7, the M-O method with $\delta=3 \phi / 4$ was assumed for the soil-foundation modeling. It is noted, however, that the scale of the force and displacement axes differs in the two figures (Figs. 7 and 8). Fig. 8 (c) is identical to the right part of Fig. 6 (a) discussed earlier. The same trend regarding the value of the shear force at node 1 relative to the shear forces at nodes 2 and 3 can be observed in both Figs. 7 and 8. Again, for all models that do not consider the pier embedment effect (Models B, C, G and H in Table 5), shear forces are higher at node 1, followed by those at node 2 and then the ones at node 3 (Figs. 8 (b), (c), (g) and (h)). The comparison of Fig. 8 (a) with Figs. 8 (b) to (c) shows that, whereas the SFS interaction and pier embedment effects do not considerably affect the response of the pier at nodes 2 and 3, the variation of shear force with displacement at node 1 differs significantly as a result of the embedment effects. For Model D (Fig. 8 (d)), the forces at all nodes are similar at small displacements, but the pier embedment effect starts picking up with increasing displacement causing a reduction of the shear force at node 1 compared to those at the other two nodes, as was the case in Fig. 7 (d). From a different perspective, the bond-slip effects of the pier in this direction are not comparable to the bond slip in the strong direction of the pier. This can be observed from the comparison of the response of Models B and C (in Figs. 8 (b) and (c), and Figs. 7 (b) and (c)), which are both fixed at their base with the former neglecting bond-slip effects and the latter incorporating them. The comparison of Figs. 8 (b) and (c) with Fig. 8 (d) shows that pier embedment effect is also significant in this direction. Furthermore, the similarity of the response of Models C and G (Figs. 8 (c) and (g)) suggests that the foundation flexibility does not significantly affect the ultimate capacity of the SFS system. In comparison to the strong direction, P- $\Delta$ effects appear to be more influential in the variation of forces along the negative weak direction of pier, where the larger plastic deformation occurs, as can be seen from the comparison of the response of Models A and E (Figs. 8 (a) and (e)); it is recalled (Table 5) that the only difference between these two models is that Model A includes P- $\Delta$ effects whereas Model E does not. Since the consideration of P- $\Delta$ effects decreases the stiffness of the pier, the nonlinear behavior along its weak direction will be amplified, and, consequently, its flexural resistance will be decreased, leading to a decrease in the shear force distribution. A similar trend in the structural response of the pier along both its strong and weak directions with the lack of consideration of its embedment and the pile cap resistance can also be observed (Figs. 7 (a) and (h), and 8 (a) and (h)). It is noted, however, that the global failure (full collapse) of Model H due to pushover along the weak direction (Fig. 8 (h)) occurs at a larger displacement $(45.54 \mathrm{~cm})$ in comparison to that along the strong direction (Fig. 7 (h)). Figs. 7 and 8 then indicate that the P- $\Delta$ effect is more important for the weak direction, and the foundation flexibility and bond-slip effects are more important for the strong direction. In addition, the pier embedment effect is influential on the structural response in both directions. 
Figs. 9 and 10 show the numerical results for the strong and negative weak direction, respectively, of the pier considering the nine different models for the SFS interaction system (Table 5), and utilizing the $\log$ spiral method with $\delta=2 \phi / 3$ in the soil-foundation modeling (more accurate approach). The comparison of Fig. 10 with Fig. 8 indicates that there is no considerable difference between the results of the analyses for the two different soil models in the negative weak direction. This suggests that the foundation flexibility estimated from two different soil modeling approaches (Fig. 4) is not very influential on the structure response in the weak direction. However, a difference occurs in the response of Models A and E in the strong direction of the pier (cf. Figs. 7 (a) and (e) with Figs. 9 (a) and (e)); this difference is in the value of the displacement where the local bond-slip failure occurs. Because the log spiral method leads to more flexible $p-y$ and $t-z$ springs, i.e., a more flexible foundation, for the models in Figs. 9 (a) and (e) the ultimate displacement is reached before bond slip occurs, but this is not the case for the models in Figs. 7 (a) and (e).

The limiting behavior of Model H (Figs. 7 (h), 8 (h), 9 (h) and 10 (h)), which neglects the pier embedment and pile cap resistance and considers only the foundation flexibility due to the pile group, indicates that the pile configuration is not efficient in increasing the rocking stiffness of the pile foundation. This may be attributed to the fact that the foundation is designed with nine long piles placed at very close distances to each other (Fig. 1(b)). For the geotechnical characteristics of the present site (Table 1), codes such as API [55], which recommend limiting values for the maximum skin friction of long piles, suggest that long piles are not very effective at depths deeper than approximately $18 \mathrm{~m}$. Therefore, from a practical viewpoint, a larger number of shorter piles connected to a wider pile cap might be a more efficient configuration than the existing one, i.e., that of nine closely spaced long piles.

To gain insight into the effects of the SFS system modeling on the results of the pushover analyses, the target ductility of each model in comparison to Model C is evaluated. Model C (Table 5) has a fixed support and incorporates the distorting bond-slip effects on the response in both directions of the pier. For the pushover analyses, the maximum displacement at the top of the pier is assumed to be one and a half times the displacement ductility of the pier modeled with Mander's concrete model (first equality of Eq. 3). The ductility demand of Model $\mathrm{C}$ along its strong and negative weak direction with the consideration of the Kent-Scott-Park concrete model can be estimated as $\mu_{\Delta}=5.33$ and 3.53, respectively, which differ from the values of $\mu_{\Delta}=3.67$ and 2.79 evaluated for Mander's model (Section 3.1). The ductility demand of the other models (except Model H), considering the flexibility of the foundation, may be obtained as [47]: 
$\mu_{\Delta}^{\prime}=1-\frac{1-\mu_{\Delta}}{1+3 \frac{\Delta_{p c}+l \theta_{p c}}{l^{2} \phi_{y}}}$

where $\Delta_{p c}$ and $\theta_{p c}$ are the lateral displacement and rotation at the top of the pile cap, respectively. For the Kent-Scott-Park concrete model, the yield curvature in Eq. 9 is obtained from Table 3 as $\phi_{y}=0.622 \times$ $10^{-3} / \mathrm{m}$ and $1.32 \times 10^{-3} / \mathrm{m}$ for the strong and weak directions, respectively. The ductility demand of Model A resting on soil modeled by the log spiral method along its strong and weak direction (Figs. 9 and 10, respectively) become $\mu_{\Delta}^{\prime}=1.78$ and 2.64 according to Eq. 9. Hence, for a constant displacement at the top of the pier, the foundation flexibility reduces the ductility demand on the pier, and this reduction is larger for the strong direction. Interestingly, the high ductility demands of the fixed-based models (Models B, C and D), which is a consequence of the unrealistic stiffness of the systems, suggest that rebar buckling may occur. On the other hand, the more realistic flexible ones (Models A, E, F, G and I), especially the "complete" Model A, lead to lower ductility demands and, hence, no rebar buckling may occur during pushover.

It can easily be shown that the ductility demand of Model $\mathrm{H}$ along its strong and weak directions are $\mu_{\Delta}^{\prime}=0.06$ and 0.21 , respectively. It is noted that Model $\mathrm{H}$ fails at displacements of $42.87 \mathrm{~cm}$ along its strong and $45.54 \mathrm{~cm}$ along its weak direction, respectively. The small values of the ductility demand corresponding to Model $\mathrm{H}$ indicate that the pier behaves rigidly in comparison to the soil during pushover. The reason of the failure of this model is due to the plastic behavior of the soil surrounding the piles, i.e. a small rotation at the pile foundation level causes a significance displacement at the top of the pier. This extreme case model illustrates how the foundation flexibility may transfer the plastic deformation from the structural elements to the foundation level due to soil-structure-interaction effects, and cause overturning of the pier due to plastic behavior of the soil.

The effect of the natural slope of the ground surface, $\beta$, on the structural behavior of the pier is investigated next. The pushover analysis is performed on Model A of the pier (Table 5) in its weak positive direction (Fig. 1 (a)) using the log spiral method with $\delta=2 \phi / 3$ for the foundation modeling. The natural slope of the ground surface is considered through the modification of the hysteretic curve corresponding to the $p-y$ springs attached to the pier and pile cap (Eq. 4). The ultimate passive pressure corresponding to the sloping ground surface is used when the pile cap displaces toward the positive weak direction of the pier. It is assumed that the sloping ground surface does not significantly affect the frictional forces because of the uncertainties related to this problem as discussed in Section 3.2.2. 
The natural slope of the ground surface is approximately $15^{\circ}$ in this direction of the second pier (Fig. 1(a)). Five additional slopes, $5^{\circ}, 10^{\circ}, 20^{\circ}, 25^{\circ}$, and $30^{\circ}$, are also considered in the evaluation to gain a better understanding of the range of the effect of the ground surface slope on this SFS system. For this embankment, the maximum slope of earth stability is conservatively estimated as $35^{\circ}$ by the $\log$ spiral method [67], given the lack of sufficient geotechnical information on the embankment soil properties. Hence, the considered variation of the ground surface slope (from a flat ground surface to a slope of $30^{\circ}$ ) is an acceptable range. The results of pushover along the positive weak direction are shown in Fig. 11. The figure indicates that the ground slope does not affect the shear force at nodes 2 and 3, but the increase of the ground slope considerably decreases the shear force at node 1 .

For pile foundations, it is commonly assumed that the maximum moment occurs in the foundation [47], as is the case for $\beta \leq 20^{\circ}$ in Fig. 11. However, the trend of the shear force variation at node 1 for the steeper slopes ( $\beta=25^{\circ}$ and $30^{\circ}$ in Fig. 11 (a)) indicates that the increase of the natural slope of the ground surface causes a shear force sign reversal, which implies that the maximum moment along the system (pier and foundation) occurs in the pier, between nodes 1 and 2 (Fig. 1 (b) and 2), instead of the pile foundation. The plastic hinge length in this case increases, a point that should be considered in the seismic design and the estimation of the rotational ductility of the pier. Since the maximum moment usually occurs at the base of piers, the plastic hinge length given in codes is evaluated only for one side of the critical section (i.e., only above the critical section or only above the base of the pier) [48]. However, both sides of the critical section (above and below the location of the maximum moment) should be considered in the estimation of the plastic hinge length, if the maximum moment occurs at a location above the base of the piers.

Fig. 12 presents the numerical results for the strong and negative weak direction of Model A of the pier considering different loading patterns, i.e. uniform, triangular and first mode shape, for the pushover analysis. The inertial force corresponding to each loading pattern is defined as the nodal mass times a predefined acceleration. The characterization of each loading pattern indicates the variation of the predefined acceleration, e.g. unit acceleration corresponding to all nodal masses is considered for the uniform loading pattern. Therefore, for the uniform loading pattern, the inertial force applied to the pier is not uniform due to its flared part. As can be seen in Fig. 12, the variation of the pier's response along each of its two directions for all three considered loading patterns is very similar. This behavior may be justified considering that: (1) the location of the plastic hinge of the pier is independent of the distribution of the inertial forces, and (2) the centroid of the area encompassing the inertial forces along the pier height is located at approximately seven-tenth of the pier height for all three loading patterns. The variations of the pier response to the triangular and first mode shape loading patterns are approximately 
the same at all three nodes of the pier. However, the difference in the pier response due to the uniform loading pattern in comparison to the two other loading patterns increases from Node 3 to Node 1 of the pier. This observation may be justified considering the fact that the contribution of the soil around the pier in absorbing the inertial force applied to the lower parts of the pier is higher than its upper parts. In spite of the fact that the location of the plastic hinge of the pier is independent of the loading pattern, the soil plasticity is sensitive to the loading pattern. Therefore, the response of the embedded part of the pier is more sensitive to the loading pattern variations due to the soil nonlinearity. Based on the numerical results presented in the Fig. 12, it may be concluded that the effect of the loading pattern on the response of the pier is not comparable to the significant effect of its model uncertainty, such as ignoring/considering the effect of the partial pier embedment.

In this study, the expected (or mean) value of the compressive strength of the concrete was considered to model the pier according to the provisions of the Caltrans [8]. However, the in-situ compressive strength of the concrete in existing structures may significantly degrade/enhance with age and is, normally, difficult to estimate. Tests on concrete cores obtained from California bridges constructed in the 1950s and 1960s indicated an increase of 1.5 to 2.7 times the specified strength of the concrete [47]. Other studies also revealed a coefficient of variation of approximately $50 \%$ in the compressive strength of the concrete of existing structures [68], [69], [70]. The Mogollon Rim Viaduct was built 25 years ago, and, hence, the effect of the uncertainty in the actual compressive strength of the concrete, $f_{c}$, on the pier response needs to be evaluated. In this pushover analysis, the loading pattern was proportional to the nodal masses of the pier. Fig. 13 compares the effect of the variations in the specified and actual (or in-situ) compressive strength of the concrete on the response of Model A of the pier along both its directions with the consideration of five different values for $f_{c}$ using the Kent-Scott-Park concrete model. The case $f_{c}=f_{c}^{\text {mean }}$ was used to analyze the behavior of the SFS system in the previous evaluations. As can be seen in Fig. 13, the required force for pushing the top of the pier up to a specified displacement increases with increasing concrete compressive strength. This observation can be attributed to the fact that the increase of the compressive strength of the concrete causes increase of the pier stiffness. The different effect of the concrete strength on the response of the pier along its strong and weak directions can also be based on the same rationale. The large stiffness along the strong direction of the pier results in the top movement of the pier being mostly controlled by the foundation rotation due to soil nonlinearity, and, therefore, the variation in the concrete strength does not significantly affect the pier response. However, for the weak direction of the pier, which has a lower stiffness, the plastic hinge at the pier base mostly controls its behavior, and, hence, the concrete strength can affect its response. 


\section{Conclusions}

In this paper, a detailed pushover analysis on one of the two piers of the Mogollon Rim Viaduct with the consideration of SFS interaction is conducted. The effects of the architecturally flared part of the pier, partial pier embedment and bond slip are incorporated in the finite-element analysis. The influence of two well-known concrete models, i.e., Mander's model and the Kent-Scott-Park model, on the pier response is studied. The traditional $p-y, t-z$ and $Q-z$ curves are used in soil-pile modeling, and equivalent nonlinear springs are derived for the modeling of the soil-pile cap and pier embedment. Two different methods for the evaluation of the ultimate passive resistance of the soil, i.e. $\mathrm{M}-\mathrm{O}$ and $\log$ spiral methods, are considered to model the foundation flexibility. In addition, the effect of the natural slope of the ground surface on the SFS system is investigated. Nine numerical models with various degrees of complexity are created to evaluate the effect of the model uncertainty of the SFS system on its pushover response. Sensitivity of the pier response to the pushover loading pattern and the variability of its concrete compressive strength were also performed. The main conclusions of this study may be summarized as follows:

- For the spalling limit state, Mander's concrete model may lead to a conservative estimation of the rotational ductility capacity of rectangular reinforced concrete sections, but an un-conservative estimation of the bond-slip effects as compared to the Kent-Scott-Park concrete model.

- It is commonly assumed that the bond resistance between the concrete and steel mostly controls the bond-slip behavior of reinforced concrete sections. However, the numerical results of the present study indicate that the concrete compression strength is also an important factor. The variations in the concrete strength leads to variations in the location of the neutral axis of the reinforced-concrete section, and, consequently, variations in the effective depth of the tension steel. For cross sections with the same geometry, reinforcement ratio, rebar size and arrangement of the reinforcement, the increase of the effective depth of the tension steel increases the bond slip.

- For tall piers with bundled longitudinal bars, bond slip at their base may occur and cause a considerable reduction in the yield and ultimate flexural strength of the pier. The maximum contribution of the bond slip to the top lateral displacement of the pier occurs at the yield displacement of the pier.

- The P- $\Delta$ effect is more pronounced in the weak direction of the pier, and the foundation flexibility and bond-slip effects are more important for its strong direction. These trends may be attributed to the differences in the stiffness and resistance characteristics of the pier along its two directions. On the other hand, the pier embedment contribution is influential on the structural response in both directions. 
- Adopting an appropriate method for the evaluation of the ultimate passive resistance of the soil is an influential factor in the seismic assessment of bridge piers. Herein, the comparison of the log spiral method (more realistic approach) with the code recommended $\mathrm{M}-\mathrm{O}$ one indicates that the former method leads to more flexible $p-y$ and $t-z$ springs, i.e., a more flexible foundation. In pushover analyses, the increase of the foundation flexibility reduces both the bond slip at the pier-pile cap connection and the ductility demand on the pier. Therefore, the model adopted for the nonlinear resistance of the soil may have a considerable influence on the pushover response of the pier structure, as illustrated by the response of the pier along its strong direction in the present study.

- Even though the effect of the passive earth pressure is commonly considered in modeling the pile cap-soil interaction, the numerical results of the present study indicate that the frictional forces in the embedded pile cap can also considerably affect the foundation flexibility. In addition, the frictional forces in the partially embedded pier can influence the force variations along the pier, and, therefore, their effect should be considered in the foundation modeling.

- The combined effect of the pier embedment and the slope of the ground surface may cause the maximum moment along the pier to occur at the upper part of its base (close to ground surface). This will increase the ductility demand of the pier and the corresponding plastic hinge length. Therefore, more caution should be applied in designing partially embedded piers located in significantly sloped sites.

- If the influence of the partial pier embedment is not considered in the finite-element modeling, the effect of the pushover loading patterns on the pier response is negligible, because their shape cannot affect the location of the formation of the plastic hinge. However, if the effect of the pier embedment is incorporated in the structural modeling, the selection of the loading pattern can affect the nonlinearity of the soil around the piers, and results in different behavior of the SFS system.

- The uncertainty in the in-situ compressive strength of the concrete may considerably affect the structural response, as, e.g. the response of the pier along its weak direction in the present study, and, hence, should be considered in the seismic assessment of the bridge.

- The use of simplified models and the lack of consideration of influential structural and geotechnical components of the SFS system, such as partial pier embedment or pile cap-soil interaction, can significantly (by more than 100\%) affect the structural response, and lead to unreliable seismic assessment of bridge piers. Therefore, adopting an appropriate approach in finite-element modeling of tall piers supported on pile foundations is essential for reducing the model uncertainty. The results herein indicate the necessity for bridge design codes to incorporate new provisions for modeling the partial pier embedment and pile cap-soil interaction. 


\section{Acknowledgments}

This study was supported by the U.S. National Science Foundation under Grant No. CMMI-0900179. Any opinions, findings, and conclusions or recommendations expressed in this material are those of the authors and do not necessarily reflect the views of the U.S. National Science Foundation.

\section{References}

1. Mylonakis, G., Nikolaou, A., Gazetas, G., Soil-pile-bridge seismic interaction: kinematic and inertial effects. Part I: soft soil, Earthquake Engineering and Structural Dynamics, Vol. 26 (1997) 337-359.

2. Wolf, J. P., Dynamic soil structure interaction, Prentice-Hall, Englewood Cliffs, N J (1985).

3. Falamarz-Sheikhabadi, M. R., Zerva, A., Analytical Seismic Assessment of a Tall Long-Span Curved Reinforced-Concrete Bridge. Part I: Numerical Modeling and Input Excitation, Journal of Earthquake Engineering, in press (2016).

4. Falamarz-Sheikhabadi, M. R., Zerva, A., Analytical Seismic Assessment of a Tall Long-Span Curved Reinforced-Concrete Bridge. Part II: Structural Response, Journal of Earthquake Engineering, in press (2016).

5. Mylonakis, G., Papastamatiou, D., Psycharis, J., Khaled, M., Simplified modeling of bridge response on soft soil to non-uniform excitation, Journal of Bridge Engineering, Vol. 6 (2001) 587-597.

6. Zerva, A., Spatial variation of seismic ground motions: modeling and engineering applications, Advances in engineering, CRC Press, Taylor \& Francis Group (2009).

7. AASHTO LRFD Bridge Design Specifications, American Association of State Highway and Transportation Officials, 2005 Interim Revisions.

8. Caltrans Seismic Design Criteria Version 1.7, California Department of Transportation Division of Engineering Services, April (2013).

9. Tsatsis, A., Kourkoulis, R., Anastasopoulos, I., Gazetas, G., Bridge pier founded on pile group: ductile design against faulting, Proceedings Innovation on bridges and soil-bridge interaction (IBSBI), Athens, Greece, 595-602 (2011).

10. Kornkasem, W., Seismic behavior of pile-supported bridges, $\mathrm{PhD}$ thesis, University of Illinois at Urbana-Champaign, (2001).

11. Minghua, Z., En, L., Jing, Y., Analysis of stability of pile foundation with higher pile-column bridge piers, Journal of Highway and Transportation Research and Development, Vol. 4 (2009) 40-44.

12. Jeremic, B., Kunnath, S., Xiong, F., Influence of soil-foundation-structure interaction on seismic response of the I-880 viaduct, Engineering Structures, Vol. 26 (2004) 391-402.

13. Shamsabadi, A., Three-dimensional nonlinear seismic soil-abutment-foundation-structure interaction analysis of skewed bridges, $\mathrm{PhD}$ thesis, University of Southern California, (2007). 
14. Falamarz-Sheikhabadi, M. R., Ghafory-Ashtiany, M., Approximate formulas for rotational effects in earthquake engineering, Journal of Seismology, Vol. 16 (2012) 815-827.

15. Falamarz-Sheikhabadi, M. R., Zerva, A., Ghafory-Ashtiany, M., Mean absolute input energy for in-plane vibrations of multiple-support structures subjected to horizontal and rocking components." Journal of Probabilistic Engineering Mechanics, Vol. 45 (2016) 87-101.

16. Trifunac, M. D., Ivanivic, S. S., Todorovska, M. I., Novikova, E. I., Gladkov, A. A., Experimental evidence for flexibility of a building foundation supported by concrete friction piles, Soil Dynamics and Earthquake Engineering, Vol. 18 (1999) 169-187.

17. Amjadian, M., Agrawal, A., Rigid-body motion of horizontally curved bridges subjected to earthquake-induced pounding, Journal of Bridge Engineering, (2016). 10.1061/(ASCE)BE.19435592.0000962, 04016090.

18. Amjadian, M., Kalantari, A., Agrawal, A. K., Analytical study of the coupled motions of decks in skew bridges with the deck-abutment collision, Journal of Vibration and Control, (2016). DOI: $10.1177 / 1077546316659781$.

19. Tirasit, P., Kawashima, K., Effect of nonlinear seismic torsion on the performance of skewed bridge piers, Journal of Earthquake Engineering, Vol. 12 (2008) 980-998.

20. Boulanger, R. W., Curras, C. J., Kutter, B. L., Wilson, D. W., Abghari, A., Seismic soil-pilestructure interaction experiments and analyses, Journal of Geotechnical and Geoenvironmental Engineering, Vol. 125 (1999) 750-759.

21. Curras, C. J., Boulanger, R. W., Kutter, B. L., Wilson, D. W., Dynamic experiments and analyses of a pile-ground-supported structure, Journal of Geotechnical and Geoenvironmental Engineering, Vol. 127 (2001) 585-596.

22. Rollins, K. M., Cole, R. T., Cyclic lateral load behavior of a pile cap and backfill, Journal of Geotechnical and Geoenvironmental Engineering, Vol. 132 (2006) 1143-1153.

23. Rollins, K. M., Sparks, A., Lateral resistance of full-scale pile cap with gravel backfill, Journal of Geotechnical and Geoenvironmental Engineering, Vol. 128 (2002) 711-723.

24. Anderson, D. G., Martin, G. R., Lam, I., Wang, J. N., Seismic analysis and design of retaining walls, buried structures, slopes, and embankments, Transportation Research Board Of The National Academies, NCHRP Report 611, (2008).

25. Comodromos, E. M., Papadopoulou, M. C., Explicit extension of the p-y method to pile groups in cohesive soils, Computers and Geotechnics, Vol. 47 (2013) 28-41.

26. Rollins, K. M., Clayton, R. J., Mikesell, R. C., Blaise, B. C., Drilled shaft side friction in gravelly soils, Journal of Geotechnical and Geoenvironmental Engineering, Vol. 131 (2005) 987-1003.

27. Mosher, R. L., Load transfer criteria for numerical analysis of axially loaded piles in sand, US Army Engineering Waterways Experimental Station, Automatic Data Processing Center, Vicksburg, Mississippi, January (1984).

28. Vijayvergiya, V. N., Load-movement characteristics of piles, Proceedings, Ports 77 Conference, American Society of Civil Engineers, Long Beach, CA, Vol. II (1977) 269-286.

29. Wang, M. C., Liao, W. P., Active length of laterally loaded piles, Journal of Geotechnical Engineering, Vol. 113 (1987) 1044-1048.

30. Cole, R. T., Rollins, K. M., Passive earth pressure mobilization during cyclic loading, Journal of Geotechnical and Geoenvironmental Engineering, Vol. 132 (2006) 1154-1164.

31. Duncan, J. M., Mokwa, R. L., Passive earth pressures: theories and tests, Journal of Geotechnical and Geoenvironmental Engineering, Vol. 127 (2001) 248-257. 
32. Guidance on the Development, Evaluation, and Application of Environmental Models, Council for Regulatory Environmental Modeling, EPA/100/K-09/003, Washington, DC (2009).

33. Taucer, F. F., Spacone, E., Filippou, F. C., A fiber beam-column element for seismic response analysis of reinforced concrete structures, Report No. UCB/EERC-91/17, (1991).

34. Mander, J. B., Priestley, M. J. N., Park, R., Theoretical stress-strain model for confined concrete, Journal of Structural Engineering, ASCE, Vol. 114 (1988) 1804-1825.

35. Kent, D. C., Park, R., Flexural members with confined concrete, Journal of the Structural Division, ASCE, Vol. 97 (1971) 51-93.

36. Scott, B. D., Park, R., Priestley, M. J. N., Stress-strain behavior of concrete confined by overlapping hoops at low and high strain rates, Journal of the American Concrete Institute, Vol. 79 (1982) 13-27.

37. Arizona Department of Transportation, Subsurface investigation Mogollon Rim Viaduct, Colcord RD. -Rim RD., Unit II, SR 260, MP 281.1, Project NO. B-053-2-411 PE (1987).

38. Mazzoni, S., McKenna, F., Scott, M. H., Fenves, G. L., et al., OpenSees Command Language Manual, University of California at Berkeley (2006).

39. Karsan, I. D., Jirsa, J. O., Behavior of concrete under compressive loading, Journal of Structural Division ASCE, Vol. 95 ST12 (1969).

40. Krauthammer, T., Forcier, G., Palmieri, L., Roth, J., Bergson, P., Discussion of "Observed stressstrain behavior of confined concrete" by Mander, J. B., Priestley, M. J. N., Park, R., Journal of Structural Engineering, Vol. 116 (1990) 1469-1471.

41. Fu, H. C., Erki, M. A., Seckin, M., Review of effects of loading rate on reinforced concrete, Journal of Structural Engineering, Vol. 117 (1991) 3660-3679.

42. Ovesen, N. K., Anchor slabs, calculation methods and model tests, Bulletin No. 16, The Danish Geotechnical Institute, Copenhagen, (1964).

43. Zhao, J., Sritharan, S., Modeling of strain penetration effects in fiber-based analysis of reinforced concrete structures, ACI Structural Journal, Vol. 104 (2007) 133-141.

44. Applied Technology Council ATC-32, Improved seismic design criteria for California bridges: provisional recommendations, Redwood City, Calif., (1996).

45. Chai, H. Y., Flexural strength and ductility of extended pile-shafts. I: Analytical model, Journal of Structural Engineering, ASCE, Vol. 128 (2002) 586-594.

46. Tanaka, H., Park, R., Effectiveness of transverse reinforcement with alternative anchorage details in reinforced concrete columns, Proceedings of the Pacific Conference on Earthquake Engineering, Wairakei, New Zealand, Vol. 1 (1987) 225-235.

47. Priestley, M. J. N., Seible, F., Calvi, G. M., Seismic design and retrofit of bridges, John Wiley \& Sons, Inc., (1996).

48. Park, R., Paulay, T., Reinforced concrete structures, John Wiley and Sons, Inc. (1975).

49. Douglas, D. J., Davis, E. H., The movements of buried footings due to moment and horizontal load and the movement of anchor plates, Geotechnique, Vol. 14 (1964) 115-132.

50. Elms, D. A., Martin, G. R., Factors involved in the seismic design of bridge abutments, Proceedings, Workshop on Seismic Problems Related to Bridges, Applied Technology Council, San Diego, California (1979).

51. Richards, R., Shi, X., Seismic lateral pressure in soils with cohesion, Journal of Geotechnical Engineering, Vol. 120 (1994) 1230-1251. 
52. Caquot, A., Kerisel, J., Tables for the calculation of passive pressure, active pressure and bearing capacity of foundations, translated by M. A. Bec, London, Gauthier-Villars, Paris (1948).

53. Shamsabadi, A., Rollins, K. M., Kapuskar, M., Nonlinear soil-abutment-bridge structure interaction for seismic performance-based design, Journal of Geotechnical and Geoenvironmental Engineering, Vol. 133 (2007) 707-720.

54. Rao, K. S. S., Choudhury, D., Seismic passive earth pressure in soils, Journal of Geotechnical and Geoenvironmental Engineering, Vol. 131 (2005) 131-135.

55. Rosenfarb, J. L., Chen, W. F., Limit analysis solutions of earth pressure problems, Fritz Engineering Laboratory Report 355.14, Lehigh University, Bethlehem, PA (1972).

56. Matsuzawa, H., Ishibashi, I., Kawamura, M., Dynamic soil and water pressures of submerged soils, Journal of Geotechnical Engineering, Vol. 111 (1985) 1161-1176.

57. Design Manual 7.02, Foundations and earth structures, Naval facilities engineering command publications transmittal (NAVAFAC DM 7.02), September (1986).

58. Mokwa, R. L., Duncan, J. M., Investigation of the resistance of the pile caps and integral abutments to lateral loadings, Virginia Transportation Research Council, Final Report: FHWA/VTRC 00-CR4, February (2000).

59. Das, M. B., Ramana, G. V., Principle of soil dynamics, Cengage Learning, Second edition (2011).

60. Bowles, E. J., Foundation analysis and design, Fifth edition, McGraw-Hill, New York (1996).

61. Recommended practice for planning, design and constructing fixed offshore platforms-working stress design, API recommended practice 2Z-WSD, (2005).

62. Kulhawy, F. H., Drilled shaft foundation, Foundation engineering handbook, second edition, H. Y. Fang, ed., Van Nostrand-Reinhold, New York (1991).

63. International Building Code (IBC), Copyright by International Code Council, INC. (2012).

64. Hain, S, J., Lee, I, K., The analysis of flexible raft-pile systems, Geotechnique, Vol. 28 (1978) 65-83.

65. Chung, L., Shah, S. P., Effect of loading rate on anchorage bond and beam-column joints, ACI Structural Journal, Vol. 86 (1989) 132-142.

66. Balafas, I., Burgoyne, C. J., Environmental effects on cover cracking due to corrosion, Cement and Concrete Research, Vol. 40 (2010) 1429-1440.

67. Fang, H. Y., Mikroudis, G. K., Stability of earth slopes, Foundation engineering handbook, second edition, H. Y. Fang, ed., Van Nostrand-Reinhold, New York (1991).

68. Timothy, P., Dolen, P. E., Materials properties model of aging concrete, U. S. Department of the Interior Bureau of Reclamation Technical Service Center, Report DSO-05-05 (2005).

69. Sakka, Z., Assakaf, I., Al-Yaqoub, T., Parol, J., Structural reliability of existing structures: A case study, International Journal of Civil, Environmental, Structural, construction and Architectural Engineering, Vol. 8 (2014) 1173-1179.

70. Shimizu, Y., Hirosawa, M., Zhou, J., Statistical analysis of concrete strength in existing reinforced concrete buildings in Japan, 12th World Conference on Earthquake Engineering, Auckland, New Zealand (2000). 


\section{List of Tables}

Table 1. Subsoil layer properties.

Table 2. Structural details of the bridge pier.

Table 3. Mechanical properties of pier sections for the two different concrete models.

Table 4. $p-y$ and $t-z$ parameters for pile cap modeling (for flat ground surface conditions).

Table 5. Description of models with different structural and geotechnical characteristics. 


\section{List of Figures}

Figure 1. Structural and geotechnical illustration of the model: (a) global model, (b) second pier characteristics (scales are not the same), and (c) equivalent single bar for the modeling of the bundled bars in the bond-slip evaluation.

Figure 2. OpenSees model for pushover analysis.

Figure 3. Comparison of the Kent-Scott-Park (part (a)) and Mander's (part (b)) concrete constitutive model effects on moment-curvature diagrams for different sections of pier along its strong (left part) and weak directions (right part). Vertical scales in the left and right plots are not to scale.

Figure 4. Nonlinear $p-y$ curves for sub cap (left part) and super cap (right part) of the pile cap evaluated with the Coulomb, Log spiral, M-O and Rankine methods. Vertical scales in the left and right plots are not to scale.Figure 5. Pile cap and pile system of the Mogollon Rim Viaduct: (a) definition of surfaces for pile caps and piles; (b) definition of $t-z$ curve for pile cap, and (c) description of effective areas for the evaluation of the resultant horizontal friction force for the top, middle and base horizontal surfaces of the pile cap.

Figure 6. Comparison of effect of the two concrete constitutive modeling approaches on model C (Table 4) of the pier system along the strong (left part) and weak (right part) direction of the pier due to pushover (node 1: black solid line, node 2: blue dashed line, node 3: red dotted line). Part (a) presents the results for the Kent-Scott- Park model, and part (b) those for Mander's model. Vertical scales in the left and right plots are not to scale.

Figure 7. Pushover analyses results along the strong direction of the pier (node 1: black solid line, node 2: blue dashed line, node 3: red dotted line); the soil model is based on the M-O method with $\delta=3 \phi / 4$.

Figure 8. Pushover analyses results along the negative weak direction of the pier (node 1: black solid line, node 2: blue dashed line, node 3: red dotted line); the soil model is based on the M-O method with $\delta=3 \phi / 4$.

Figure 9. Pushover analyses results along the strong direction of the pier (node 1: black solid line, node 2: blue dashed line, node 3: red dotted line); the soil model is based on the log spiral method with $\delta=2 \phi / 3$.

Figure 10. Pushover analyses results along the negative weak direction of the pier (node 1: black solid line, node 2: blue dashed line, node 3: red dotted line); the soil model is based on the log spiral method with $\delta=2 \phi / 3$. 
Figure 11. Pushover analyses results along the positive weak direction of the pier for Model A; the soil model is based on the log spiral method with $\delta=2 \phi / 3$.

Figure 12. Pushover analyses results along the strong and negative weak direction of the pier for Model A considering different loading patterns; the soil model is based on the log spiral method with $\delta=2 \phi / 3$.

Figure 13. Pushover analyses results along the strong and negative weak direction of the pier for Model A considering different values for the actual compressive strength of the concrete; the soil model is based on the $\log$ spiral method with $\delta=2 \phi / 3$. 
Table 1. Subsoil layer properties [37].

\begin{tabular}{|c|c|c|c|c|c|c|}
\hline $\begin{array}{c}\text { Soil } \\
\text { layer }\end{array}$ & $\begin{array}{c}\text { Depth } \\
(\mathrm{m})\end{array}$ & Soil type & $\begin{array}{c}\text { Dry unit weight } \\
\left(\mathrm{kN} / \mathrm{m}^{3}\right)\end{array}$ & $\begin{array}{c}\text { Internal friction } \\
\text { angle }(\mathrm{deg})\end{array}$ & $\begin{array}{c}\text { Density ratio } \\
(\%)\end{array}$ & $\begin{array}{c}\text { SPT } \\
(\text { blows/ft })\end{array}$ \\
\hline Layer 1 & $0-1.52$ & Loose sand & 0.0117 & 30 & 25 & 9 \\
\hline Layer 2 & $1.52-4.57$ & Medium sand & 0.0141 & 35 & 55 & 21 \\
\hline Layer 3 & $4.57-9.14$ & Dense sand & 0.0165 & 38 & 70 & 38 \\
\hline Layer 4 & $9.14-34.7$ & $\begin{array}{c}\text { Very dense } \\
\text { sand }\end{array}$ & 0.0180 & 40 & 80 & 76 \\
\hline
\end{tabular}

Table 2. Structural details of the bridge pier.

\begin{tabular}{|c|c|c|c|c|c|c|}
\hline $\begin{array}{l}\text { Section } \\
\text { number }\end{array}$ & $\begin{array}{c}\text { Gross area } \\
\text { of section } \\
\left(m^{2}\right)\end{array}$ & $\begin{array}{l}\text { Longitudinal } \\
\text { reinforcement } \\
\text { ratio }\end{array}$ & $\begin{array}{l}\text { Number of } \\
\text { concrete } \\
\text { fibers }\end{array}$ & $\begin{array}{l}\text { Number of } \\
\text { steel fibers }\end{array}$ & $\begin{array}{c}\text { Number of } \\
\text { integration } \\
\text { points of } \\
\text { each element }\end{array}$ & $\begin{array}{l}\text { Axial load } \\
\text { ratio }\end{array}$ \\
\hline Section 1 & 15.05 & 0.0102 & 432 & 76 & $5^{*}$ & 0.071 \\
\hline Section 2 & 15.88 & 0.0096 & 432 & 76 & 5 & 0.066 \\
\hline Section 3 & 17.55 & 0.0091 & 432 & 92 & 5 & 0.058 \\
\hline Section 4 & 19.23 & 0.0086 & 432 & 108 & 3 & 0.052 \\
\hline Section 5 & 20.90 & 0.0082 & 432 & 124 & 3 & 0.047 \\
\hline Section 6 & 22.57 & 0.0079 & 432 & 140 & 3 & 0.043 \\
\hline
\end{tabular}

${ }^{*} 3$ integration points are considered for the first element at the pier base.

Table 3. Mechanical properties of pier sections for the two different concrete models.

\begin{tabular}{|c|c|c|c|c|c|c|c|c|c|}
\hline \multirow{2}{*}{$\begin{array}{l}\text { Section } \\
\text { number }\end{array}$} & \multirow{2}{*}{$\begin{array}{c}\text { Pier } \\
\text { direction }\end{array}$} & \multirow{2}{*}{$\begin{array}{c}\text { Effective } \\
\text { depth } \\
(m)\end{array}$} & \multirow{2}{*}{$\begin{array}{c}\text { Axial } \\
\text { load } \\
(k N)\end{array}$} & \multicolumn{3}{|c|}{$\begin{array}{c}\text { Kent-Scott-Park concrete } \\
\text { model }\end{array}$} & \multicolumn{3}{|c|}{ Mander concrete model } \\
\hline & & & & $\begin{array}{c}\text { Yield } \\
\text { curvature } \\
\left(1 / m^{*} 10^{-3}\right)\end{array}$ & $\begin{array}{l}\text { Rotational } \\
\text { ductility }\end{array}$ & $M_{u} / M_{y}$ & $\begin{array}{c}\text { Yield } \\
\text { curvature } \\
\left(1 / m^{*} * 10^{-3}\right)\end{array}$ & $\begin{array}{l}\text { Rotational } \\
\text { ductility }\end{array}$ & $M_{u} / M_{y}$ \\
\hline \multirow{2}{*}{$\begin{array}{c}\text { Section } \\
1\end{array}$} & strong & 5.38 & \multirow{2}{*}{36911} & 0.622 & 10 & 1.295 & 0.728 & 7.69 & 1.271 \\
\hline & weak & 2.59 & & 1.32 & 7.1 & 2 & 1.42 & 5.00 & 1.156 \\
\hline \multirow{2}{*}{$\begin{array}{l}\text { Section } \\
2 \\
\end{array}$} & strong & 5.53 & \multirow{2}{*}{36288} & 0.602 & 5.76 & 1.265 & 0.677 & 4.25 & 1.231 \\
\hline & weak & 2.59 & & 1.35 & 8.14 & 1.183 & 1.42 & 5.27 & 1.159 \\
\hline \multirow{2}{*}{$\begin{array}{c}\text { Section } \\
3\end{array}$} & strong & 6.09 & \multirow{2}{*}{35341} & 0.598 & 6.2 & 1.249 & 0.654 & 5.50 & 1.217 \\
\hline & weak & 2.59 & & 1.36 & 9.19 & 1.191 & 1.42 & 6.04 & 1.168 \\
\hline \multirow{2}{*}{$\begin{array}{c}\text { Section } \\
4 \\
\end{array}$} & strong & 6.74 & \multirow{2}{*}{34705} & 0.531 & 5.98 & 1.264 & 0.591 & 5.0 & 1.227 \\
\hline & weak & 2.59 & & 1.31 & 10.14 & 1.219 & 1.40 & 6.89 & 1.179 \\
\hline \multirow{2}{*}{$\begin{array}{c}\text { Section } \\
5\end{array}$} & strong & 7.39 & \multirow{2}{*}{34153} & 0.524 & 5.66 & 1.255 & 0.575 & 5.00 & 1.214 \\
\hline & weak & 2.59 & & 1.30 & 10.57 & 1.206 & 1.40 & 7.56 & 1.186 \\
\hline \multirow{2}{*}{$\begin{array}{c}\text { Section } \\
6\end{array}$} & strong & 8.04 & \multirow{2}{*}{33624} & 0.496 & 5.99 & 1.258 & 0.551 & 5.00 & 1.215 \\
\hline & weak & 2.59 & & 1.39 & 10.54 & 1.219 & 1.35 & 8.37 & 1.200 \\
\hline
\end{tabular}


Table 4. $p-y$ and $t-z$ parameters for pile cap modeling (for flat ground surface conditions).

\begin{tabular}{|c|c|c|c|c|c|c|c|c|c|c|}
\hline \multicolumn{11}{|c|}{ Nonlinear springs corresponding to passive earth forces } \\
\hline Pile cap & $\begin{array}{l}\text { p-y spring } \\
\text { location }\end{array}$ & \multicolumn{2}{|c|}{$\begin{array}{c}\text { Depth } \\
(m)\end{array}$} & $\begin{array}{c}\text { Width } \\
(m)\end{array}$ & \multicolumn{2}{|c|}{$\begin{array}{l}\text { Length } \\
\text { (m) }\end{array}$} & $\begin{array}{c}\boldsymbol{P}_{\text {ult with }} \\
\text { M-O } \\
(k N)\end{array}$ & $\begin{array}{c}\text { Pult with } \\
\text { Log spiral } \\
(k N)\end{array}$ & $\begin{array}{c}\boldsymbol{k}_{\max } \\
(\mathrm{kN} / \mathrm{m})\end{array}$ & $\boldsymbol{R}_{\boldsymbol{f}}$ \\
\hline Super cap & Center & \multicolumn{2}{|c|}{2.286} & 5.486 & \multicolumn{2}{|c|}{5.486} & 21222 & 16218 & 86657 & 0.85 \\
\hline Sub cap & Center & \multicolumn{2}{|c|}{2.286} & 9.144 & \multicolumn{2}{|c|}{9.144} & 49215 & 37640 & 231765 & 0.85 \\
\hline \multicolumn{11}{|c|}{ Nonlinear springs corresponding to frictional forces } \\
\hline \multirow[t]{2}{*}{$\begin{array}{c}\text { Ultimate } \\
\text { frictional } \\
\text { capacity } \\
\left(t_{u l t}\right)\end{array}$} & \multicolumn{2}{|c|}{$\begin{array}{c}\text { Base horizontal } \\
\text { surface - applied in } \\
\text { both horizontal } \\
\text { directions } \\
(k N)\end{array}$} & \multicolumn{3}{|c|}{$\begin{array}{c}\text { Middle horizontal } \\
\text { surface - applied in both } \\
\text { horizontal directions } \\
(k N)\end{array}$} & \multicolumn{2}{|c|}{$\begin{array}{c}\text { Top horizontal } \\
\text { surface - applied in } \\
\text { strong direction only } \\
(k N)\end{array}$} & $\begin{array}{c}\text { Side of } \\
\text { super cap } \\
(k N)\end{array}$ & \multicolumn{2}{|c|}{$\begin{array}{c}\text { Side of sub cap } \\
(k N)\end{array}$} \\
\hline & \multicolumn{2}{|c|}{16400} & \multicolumn{3}{|c|}{3349} & \multicolumn{2}{|r|}{564} & 3518 & \multicolumn{2}{|c|}{6040} \\
\hline
\end{tabular}

Table 5. Description of models with different structural and geotechnical characteristics.

\begin{tabular}{|c|c|c|c|c|c|c|c|c|c|}
\hline $\begin{array}{l}\text { Effective structural and } \\
\text { geotechnical parameters }\end{array}$ & $\begin{array}{c}\text { Model } \\
\text { A }\end{array}$ & $\begin{array}{c}\text { Model } \\
\text { B }\end{array}$ & $\begin{array}{c}\text { Model } \\
\text { C }\end{array}$ & $\begin{array}{c}\text { Model } \\
\text { D }\end{array}$ & $\begin{array}{c}\text { Model } \\
\text { E }\end{array}$ & $\begin{array}{c}\text { Model } \\
\text { F }\end{array}$ & $\begin{array}{c}\text { Model } \\
\text { G }\end{array}$ & $\begin{array}{c}\text { Model } \\
\text { H }\end{array}$ & $\begin{array}{c}\text { Model } \\
\text { I }\end{array}$ \\
\hline Fixed base & No & Yes & Yes & Yes & No & No & No & No & No \\
\hline$P$ - $\Delta$ effect & Yes & Yes & Yes & Yes & No & Yes & Yes & Yes & Yes \\
\hline Bond-slip effect & Yes & No & Yes & Yes & Yes & No & Yes & Yes & Yes \\
\hline $\begin{array}{c}\text { Passive earth pressure effects } \\
\text { on partially embedded pier }\end{array}$ & Yes & No & No & Yes & Yes & Yes & No & No & Yes \\
\hline $\begin{array}{c}\text { Frictional force effects on } \\
\text { partially embedded pier }\end{array}$ & Yes & No & No & Yes & Yes & Yes & No & No & No \\
\hline $\begin{array}{c}\text { Passive earth pressure effects } \\
\text { on pile cap resistance }\end{array}$ & Yes & No & No & No & Yes & Yes & Yes & No & Yes \\
\hline $\begin{array}{c}\text { Frictional force effects on pile } \\
\text { cap resistance }\end{array}$ & Yes & No & No & No & Yes & Yes & Yes & No & No \\
\hline Pile-to-soil interaction & Yes & No & No & No & Yes & Yes & Yes & Yes & Yes \\
\hline
\end{tabular}



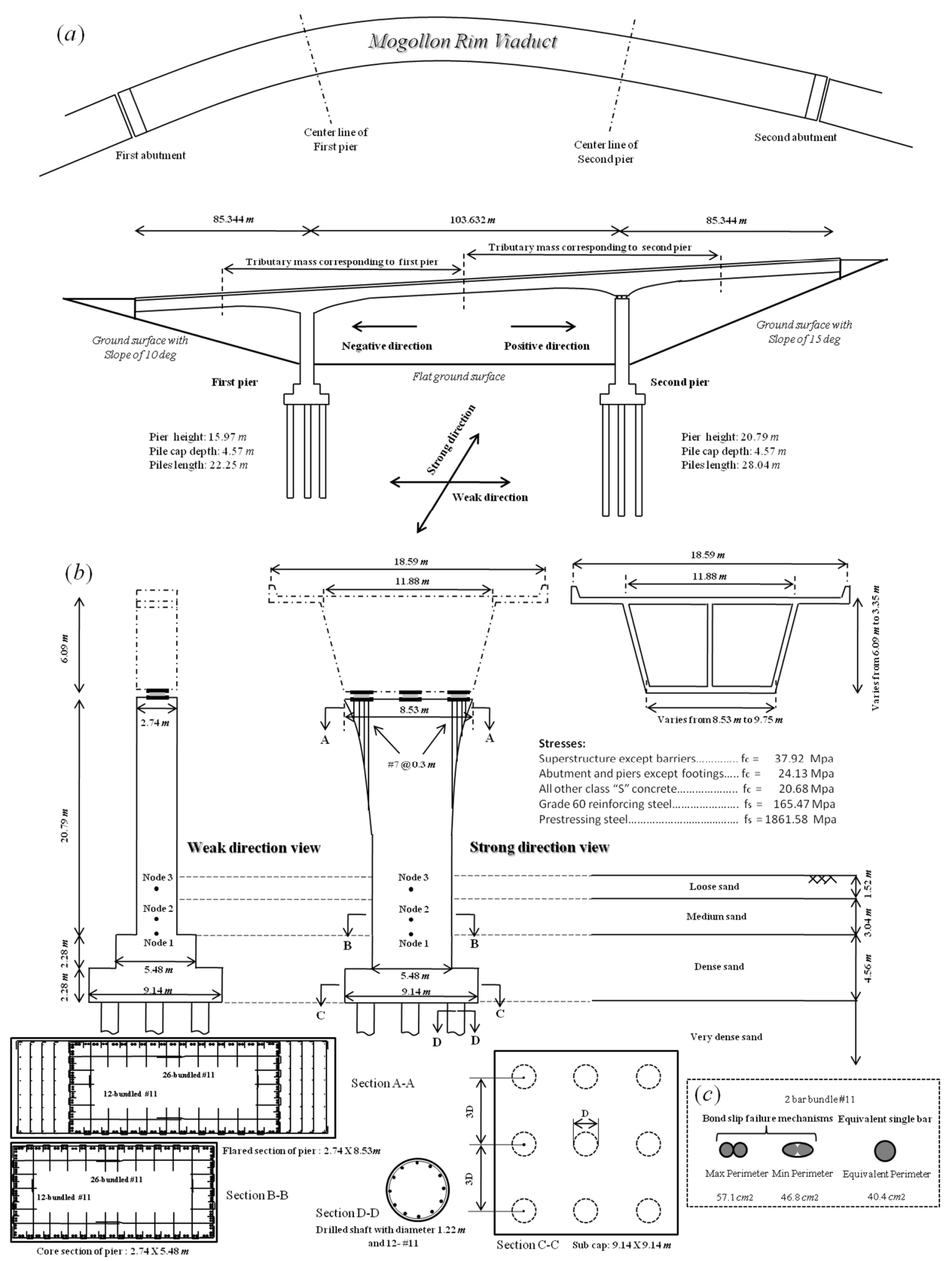

Figure 1. Structural and geotechnical illustration of the model: (a) global model, (b) second pier characteristics (scales are not the same), and (c) equivalent single bar for the modeling of the bundled bars in the bond-slip evaluation. 


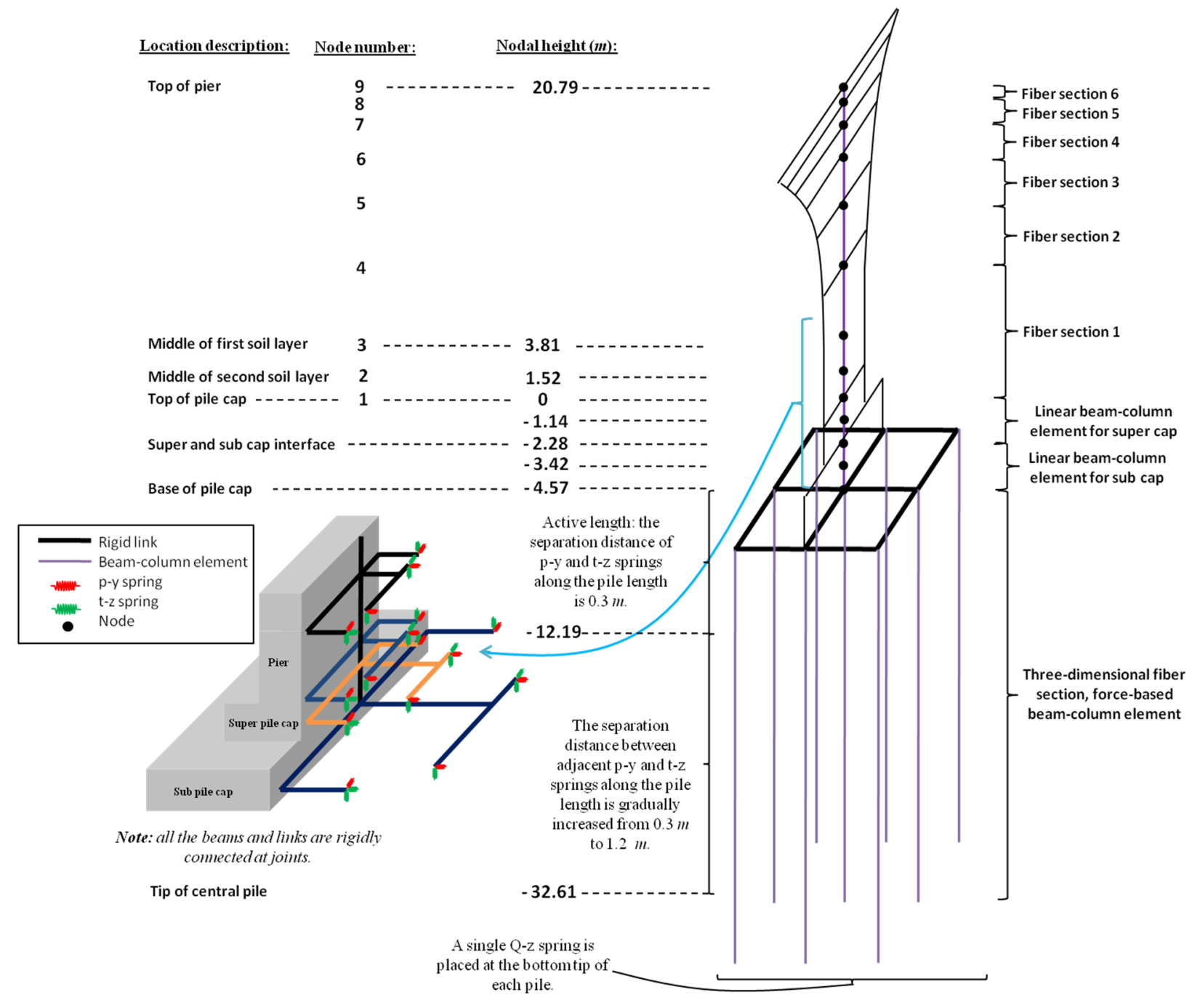

Figure 2. OpenSees model for pushover analysis. 
Strong direction

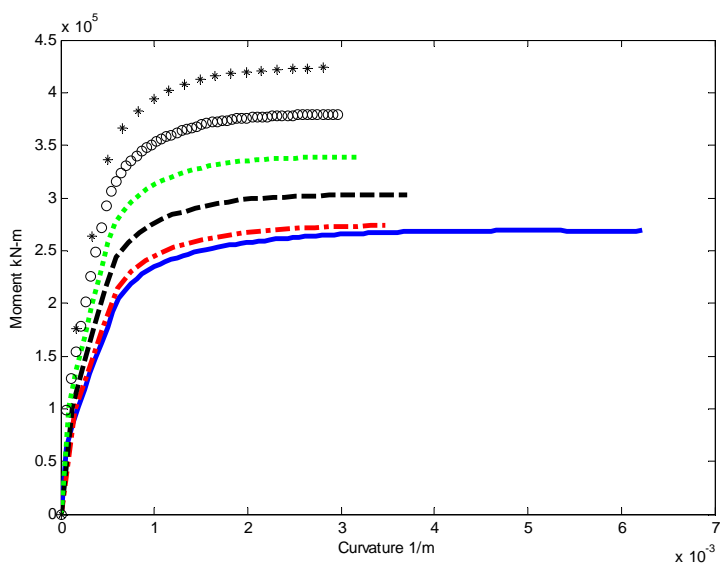

Weak direction

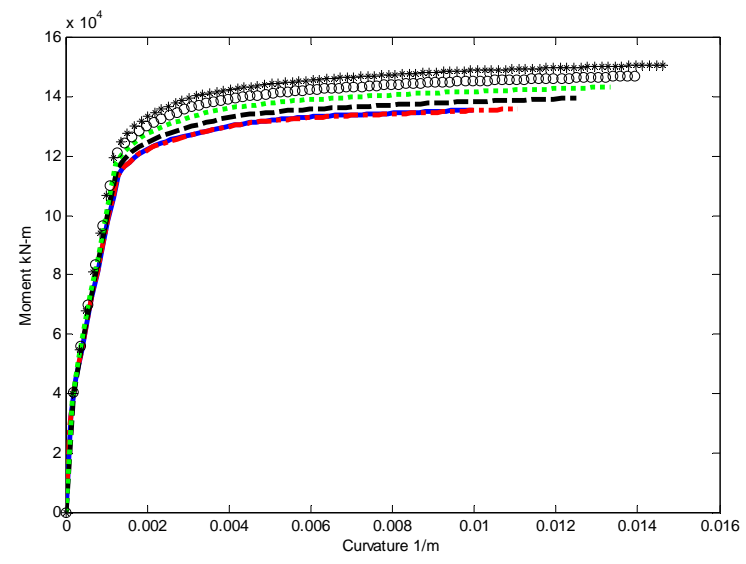

(a) Kent-Scott-Park concrete model
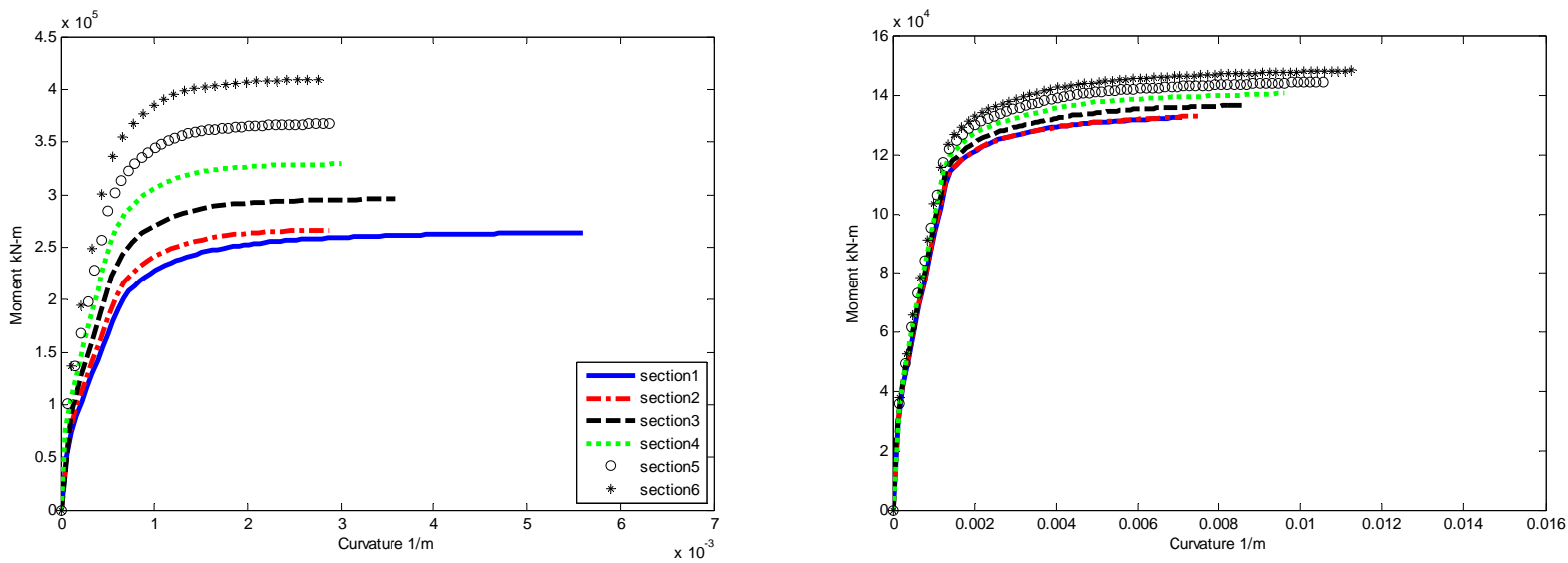

(b) Mander concrete model

Figure 3. Comparison of the Kent-Scott-Park (part (a)) and Mander's (part (b)) concrete constitutive model effects on moment-curvature diagrams for different sections of pier along its strong (left part) and weak directions (right part). Vertical scales in the left and right plots are not to scale. 

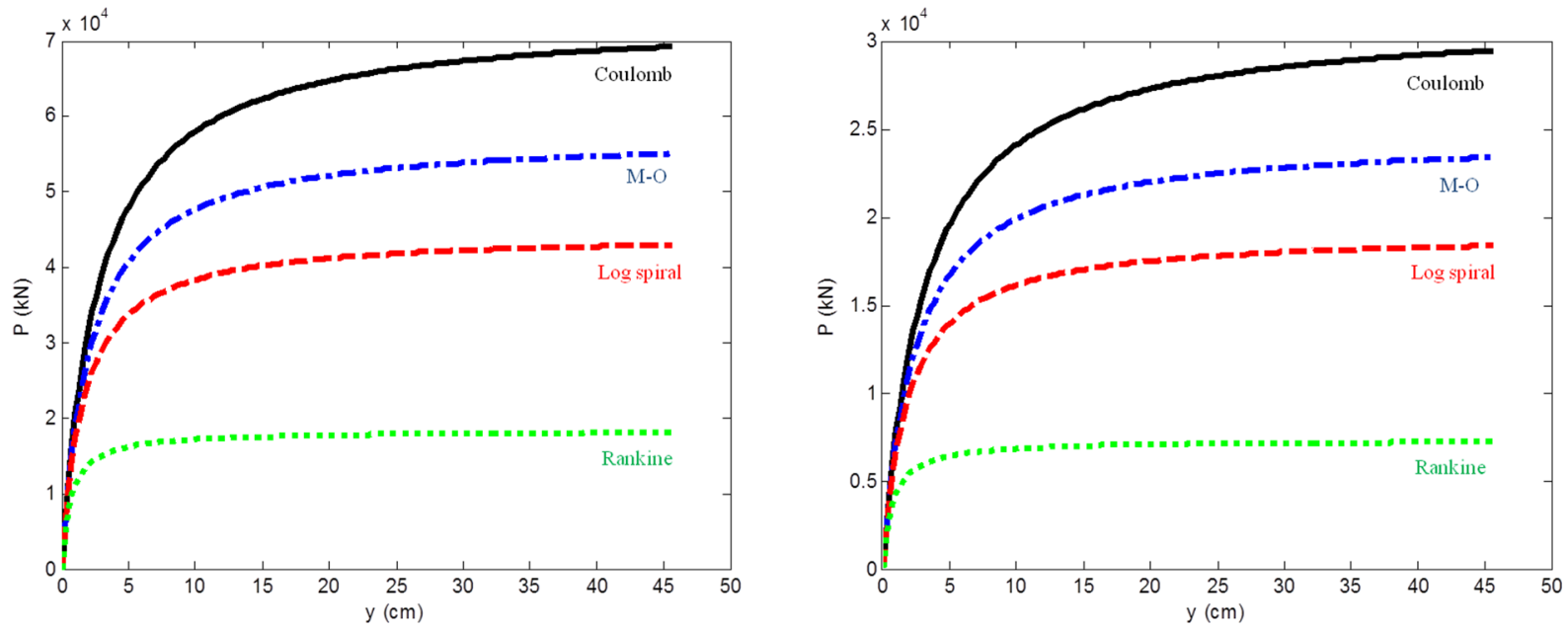

Figure 4. Nonlinear $p-y$ curves for sub cap (left part) and super cap (right part) of the pile cap evaluated with the Coulomb, Log spiral, M-O and Rankine methods. Vertical scales in the left and right plots are not to scale. 

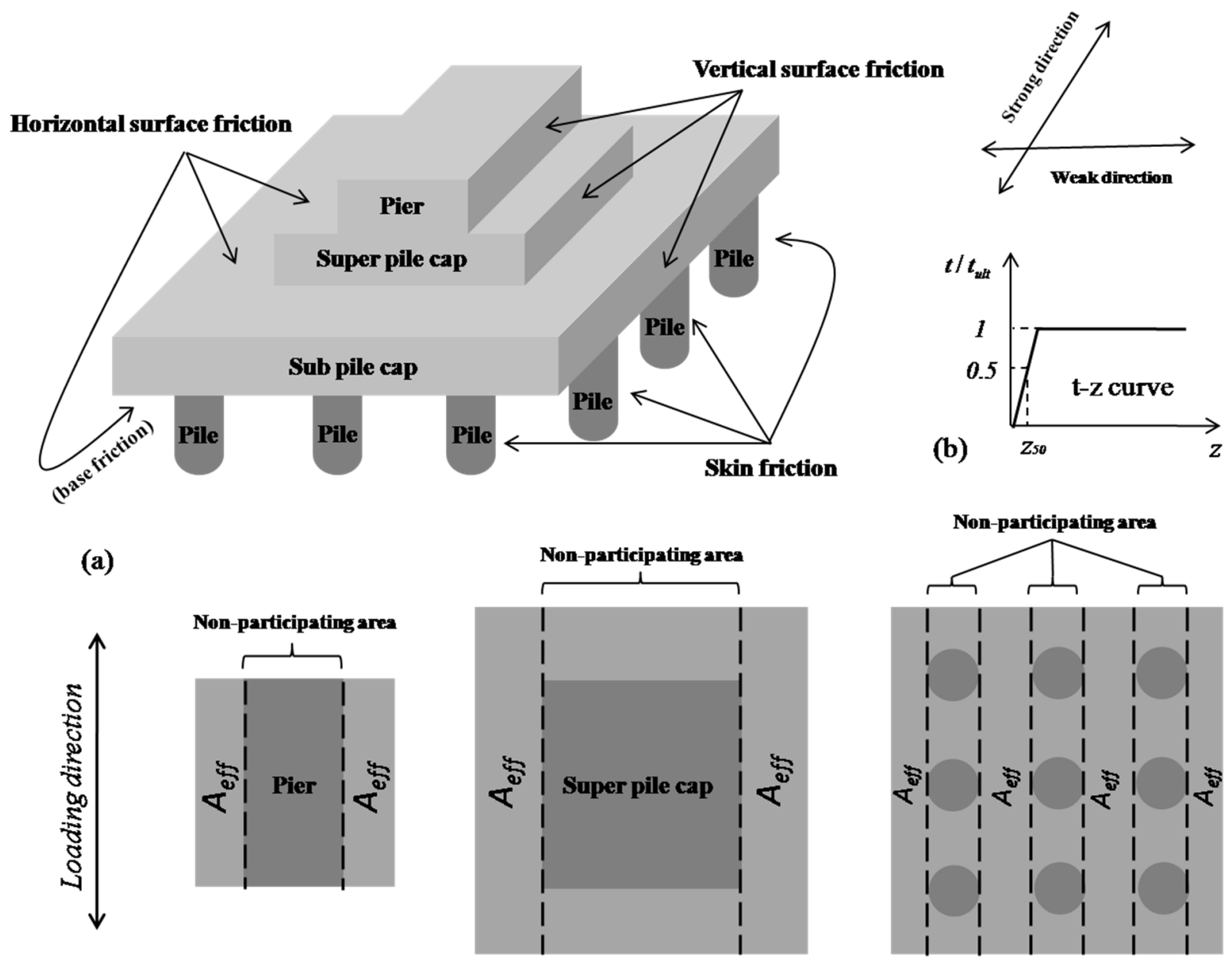

(c) Top horizontal surface Middle horizontal surface

Base horizontal surface

Figure 5. Pile cap and pile system of the Mogollon Rim Viaduct: (a) definition of surfaces for pile caps and piles; (b) definition of $t-z$ curve for pile cap, and (c) description of effective areas for the evaluation of the resultant horizontal friction force for the top, middle and base horizontal surfaces of the pile cap. 
Strong direction

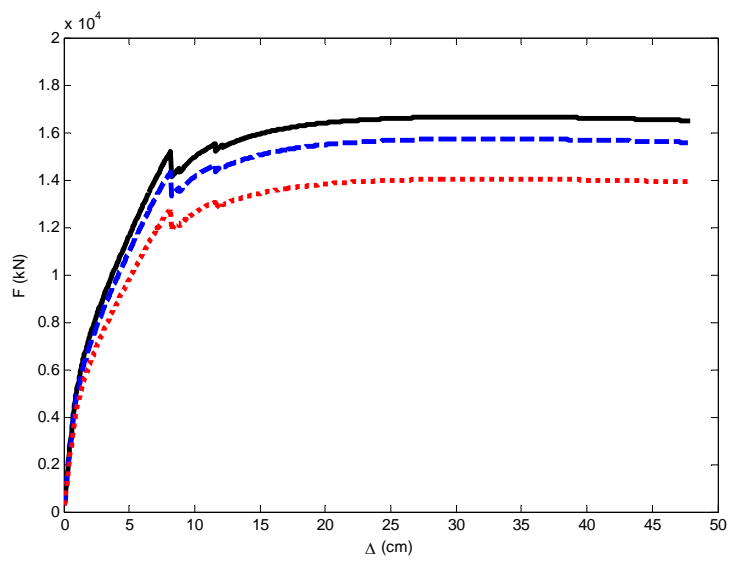

Weak direction

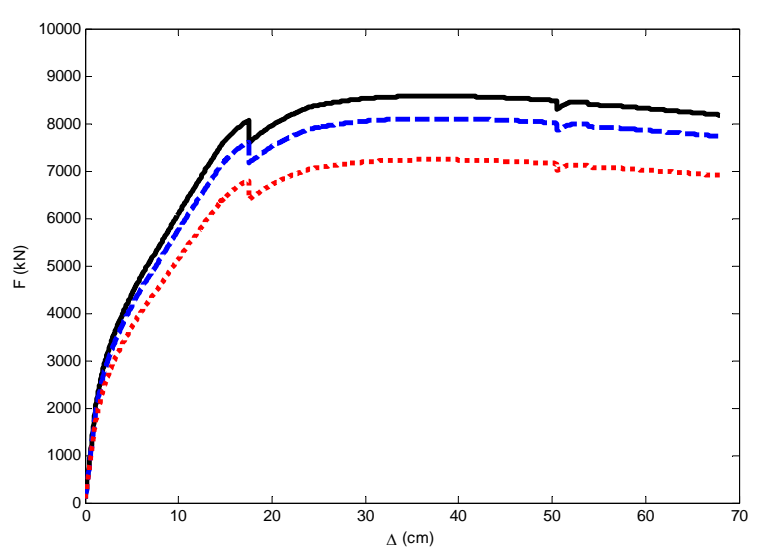

(a) Kent-Scott-Park concrete model
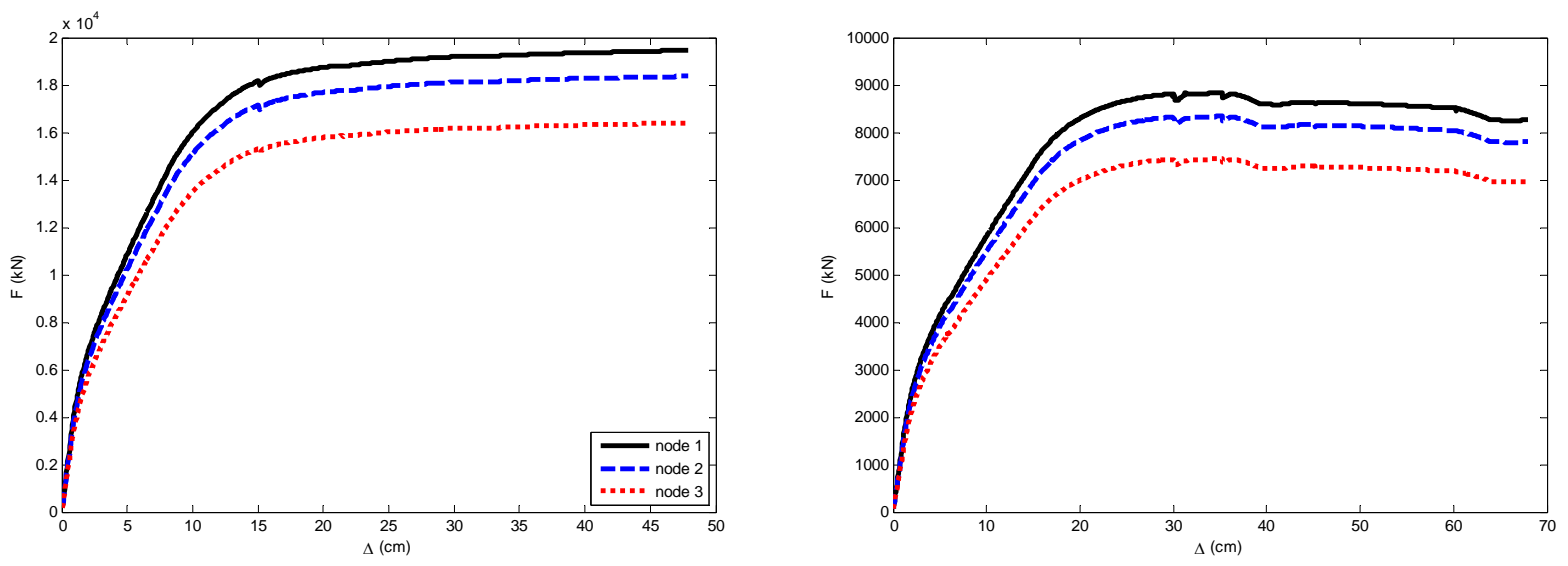

(b) Mander concrete model

Figure 6. Comparison of effect of the two concrete constitutive modeling approaches on model C (Table 4) of the pier system along the strong (left part) and weak (right part) direction of the pier due to pushover (node 1: black solid line, node 2: blue dashed line, node 3: red dotted line). Part (a) presents the results for the Kent-Scott- Park model, and part (b) those for Mander's model. Vertical scales in the left and right plots are not to scale. 


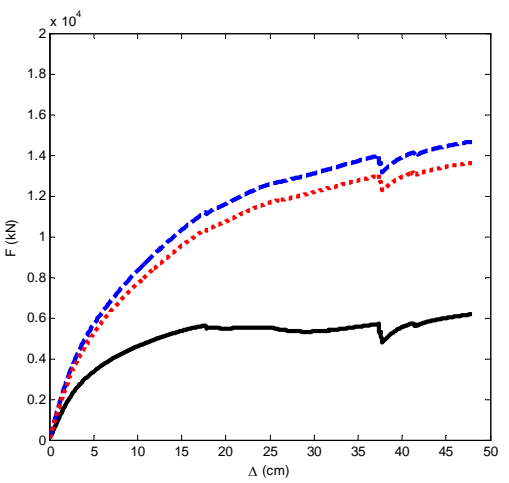

(a) Model A

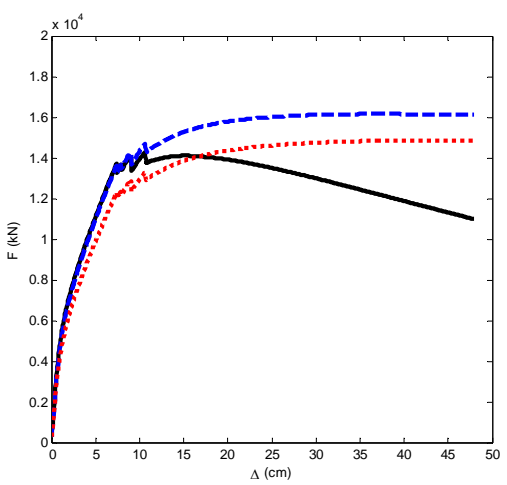

(d) Model D

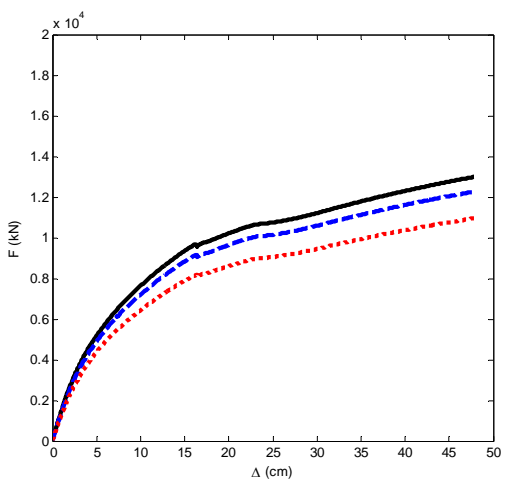

(g) Model G

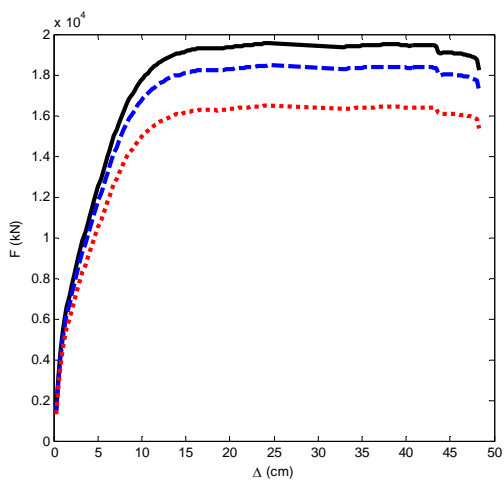

(b) Model B

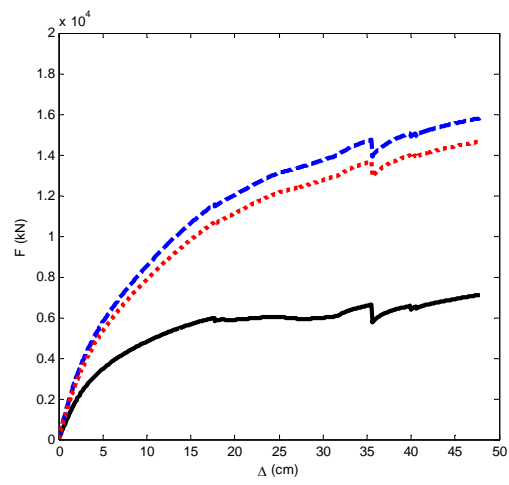

(e) Model E

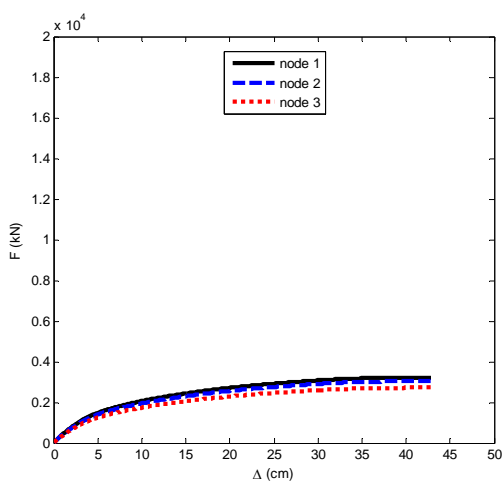

(h) Model H

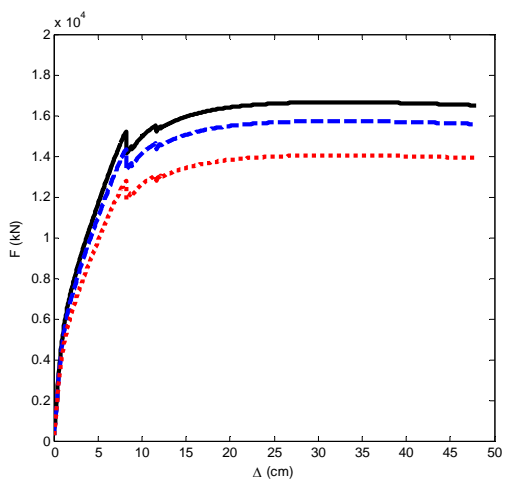

(c) Model C

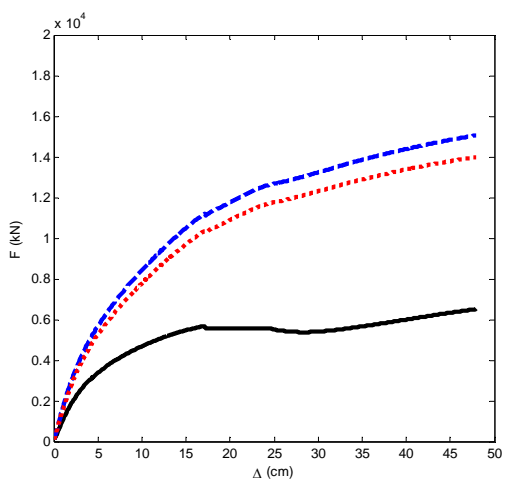

(f) Model F

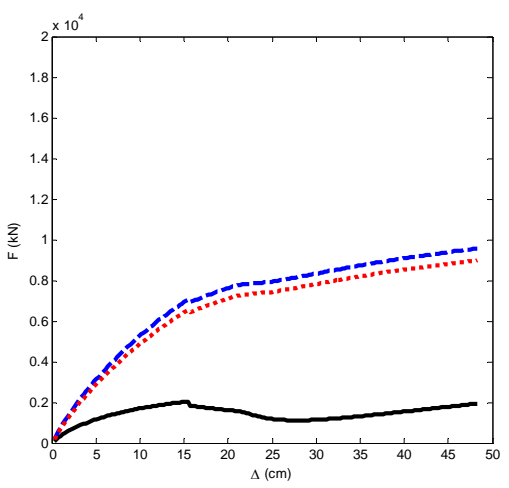

(i) Model I

Figure 7. Pushover analyses results along the strong direction of the pier (node 1: black solid line, node 2: blue dashed line, node 3: red dotted line); the soil model is based on the M-O method with $\delta=3 \phi / 4$. 


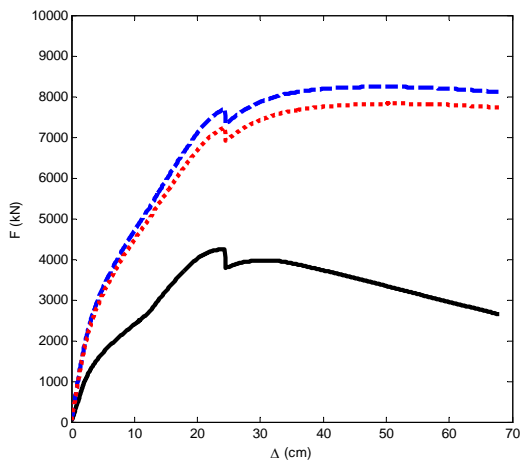

(a) Model A

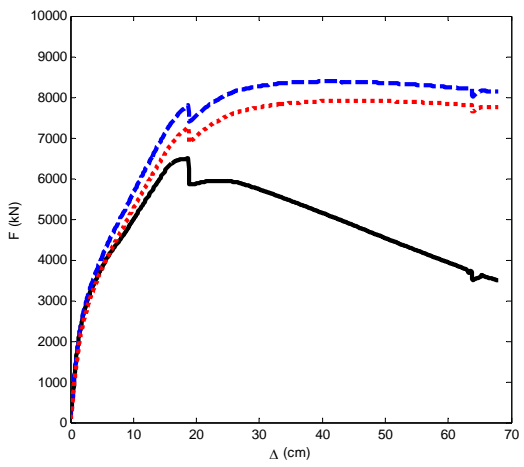

(d) Model D

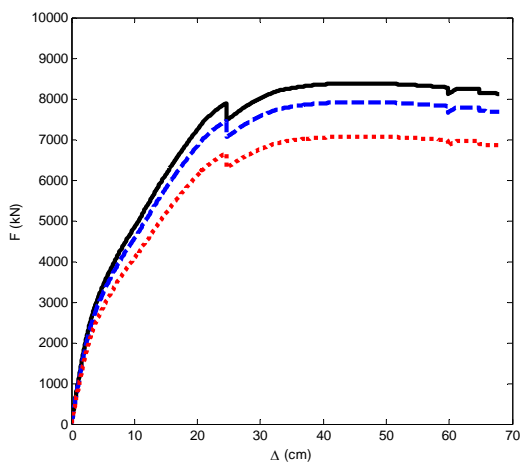

(g) Model G

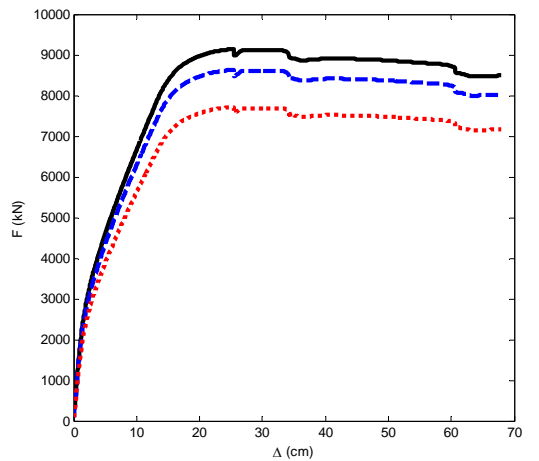

(b) Model B

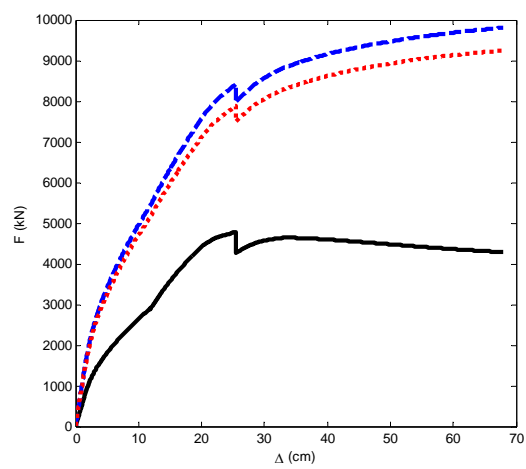

(e) Model E

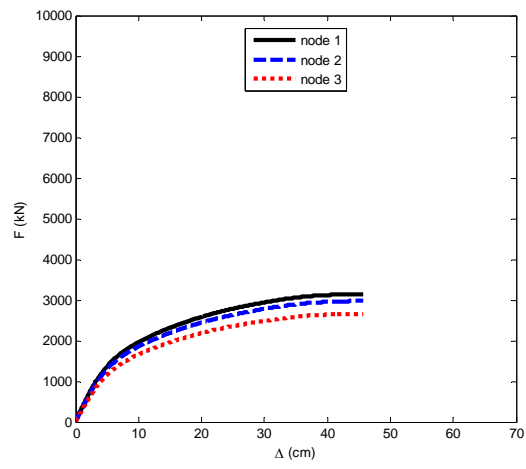

(h) Model H

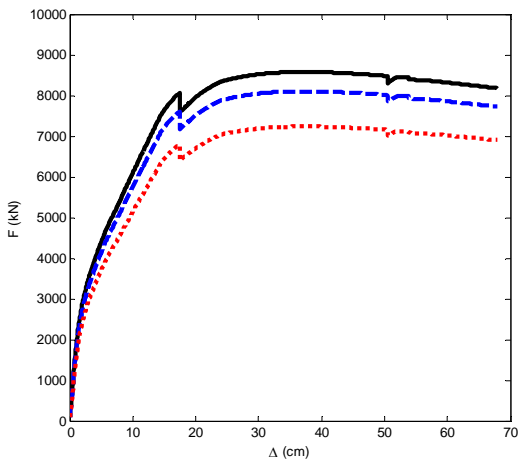

(c) Model C

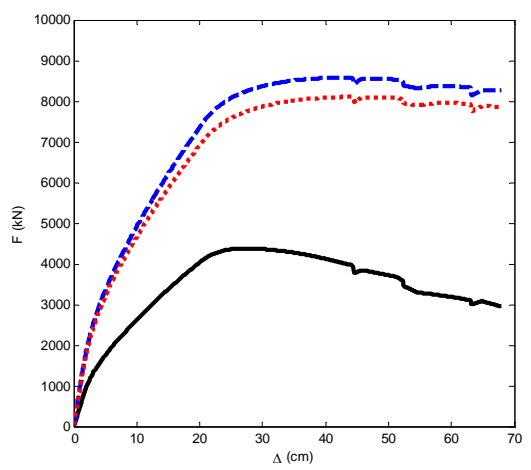

(f) Model F

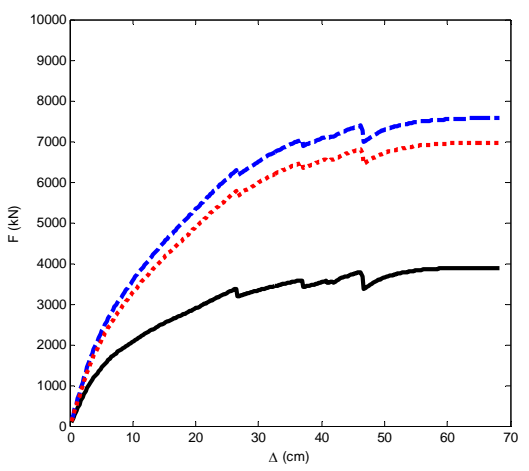

(i) Model I

Figure 8. Pushover analyses results along the negative weak direction of the pier (node 1: black solid line, node 2: blue dashed line, node 3: red dotted line); the soil model is based on the M-O method with $\delta=3 \phi / 4$. 


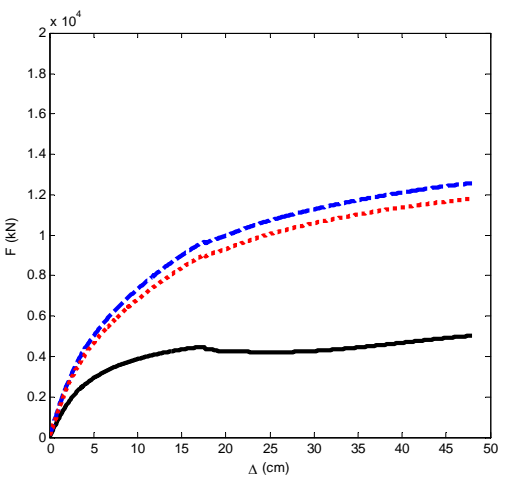

(a) Model A

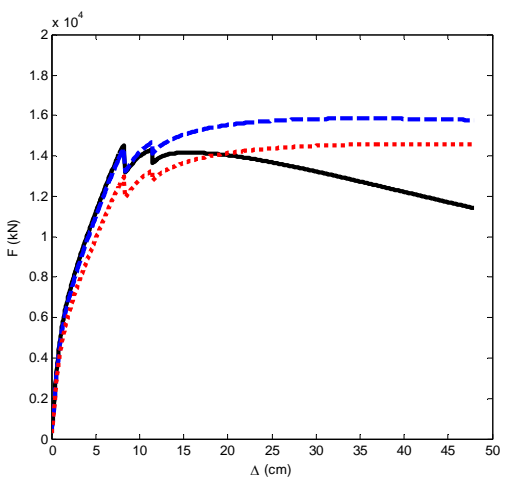

(d) Model D

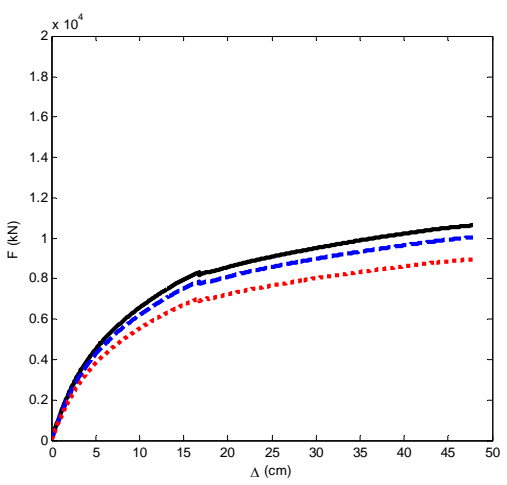

(g) Model G

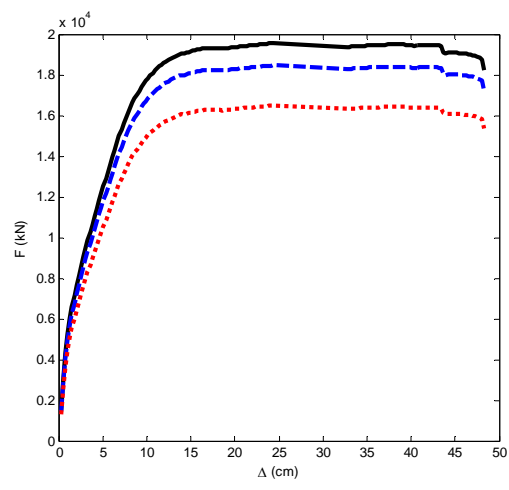

(b) Model B

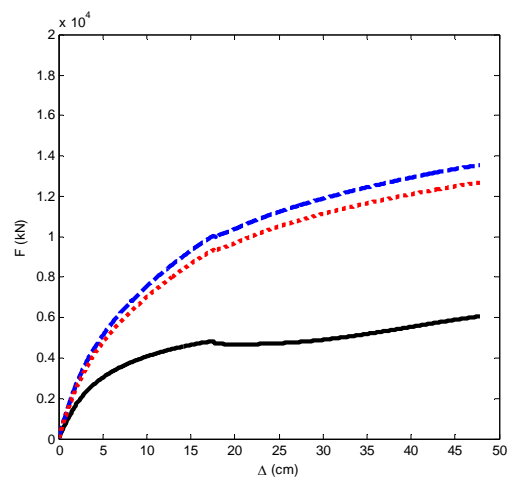

(e) Model E

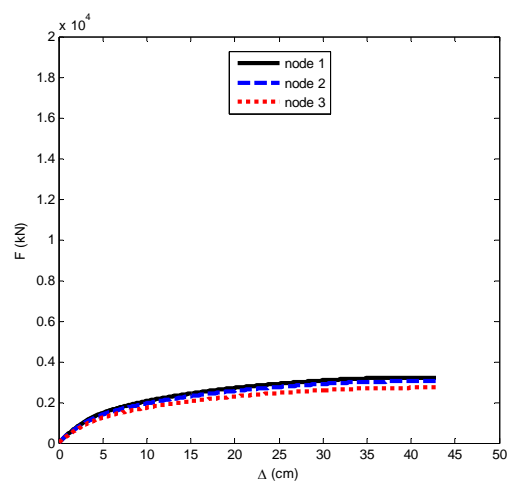

(h) Model H

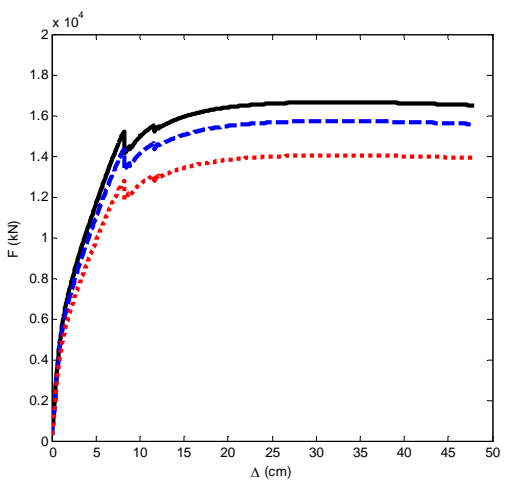

(c) Model C

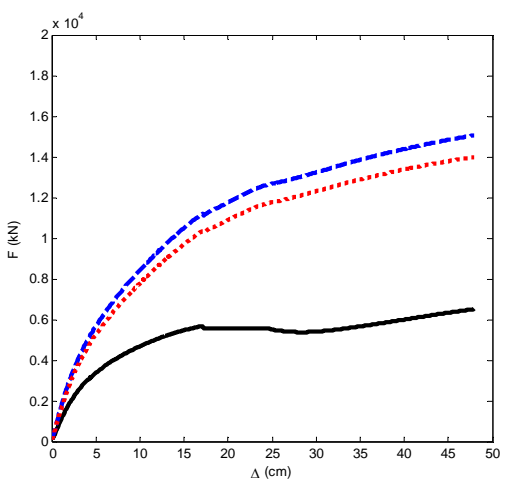

(f) Model F

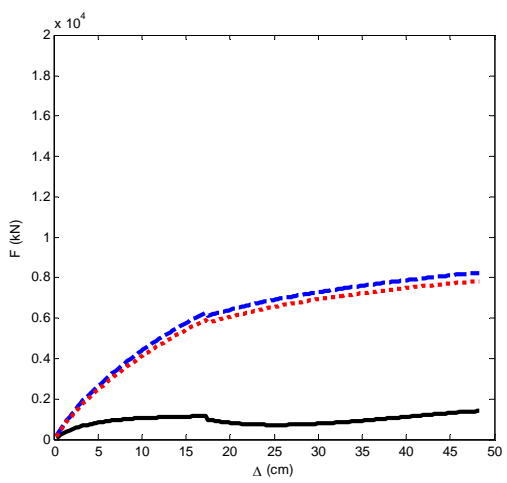

(i) Model I

Figure 9. Pushover analyses results along the strong direction of the pier (node 1: black solid line, node 2: blue dashed line, node 3: red dotted line); the soil model is based on the log spiral method with $\delta=2 \phi / 3$. 


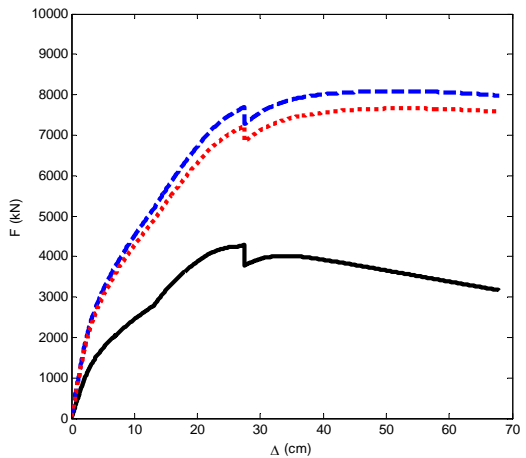

(a) Model A

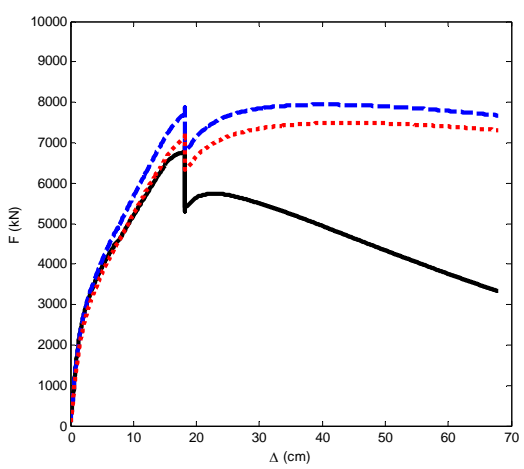

(d) Model D

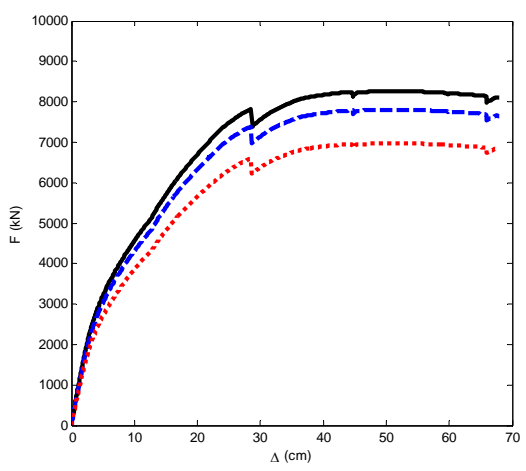

(g) Model G

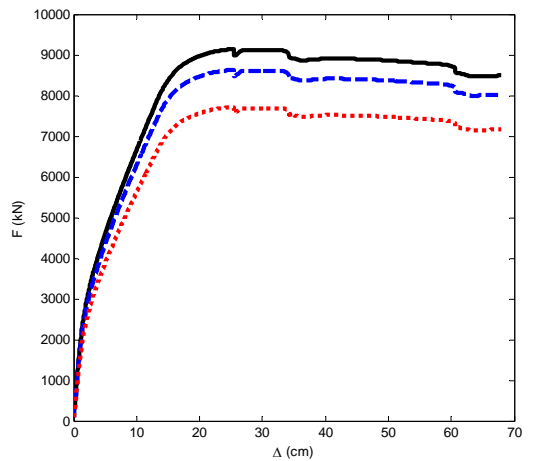

(b) Model B

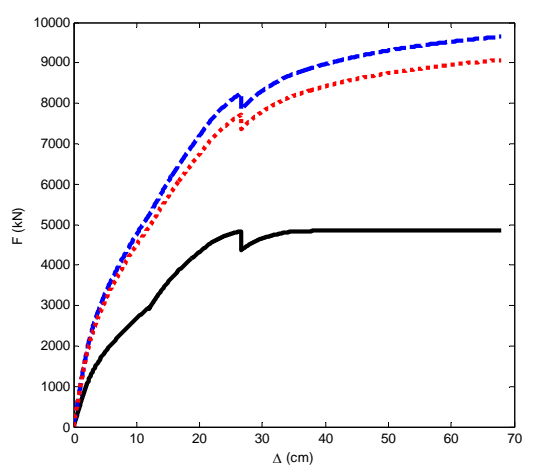

(e) Model E

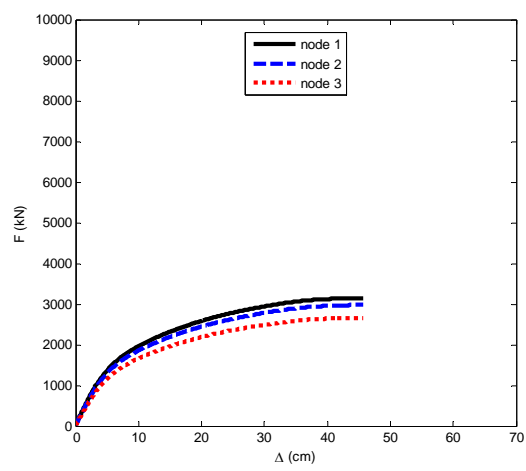

(h) Model H

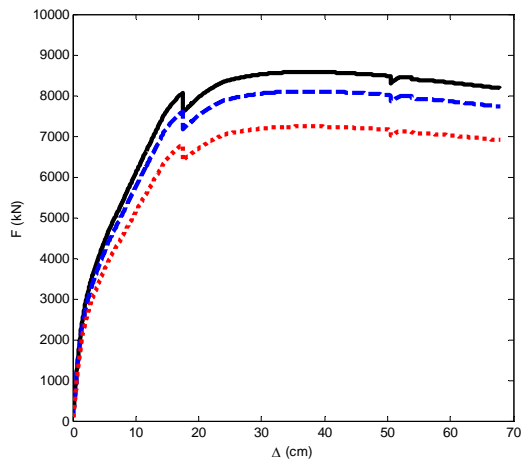

(c) Model C

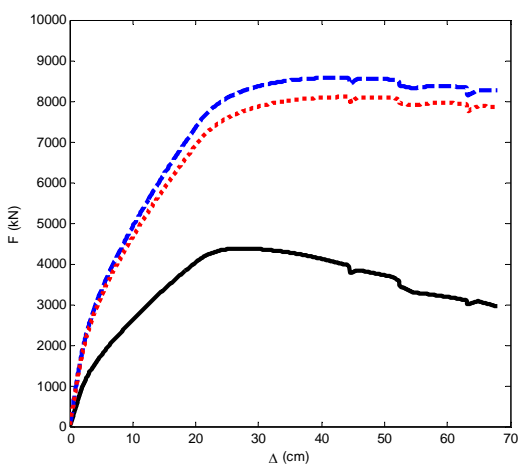

(f) Model F

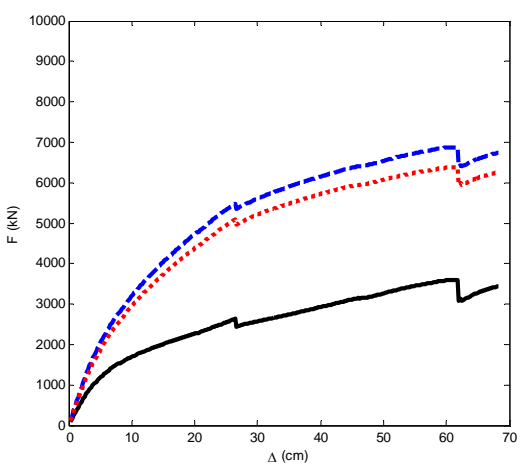

(i) Model I

Figure 10. Pushover analyses results along the negative weak direction of the pier (node 1: black solid line, node 2: blue dashed line, node 3: red dotted line); the soil model is based on the log spiral method with $\delta=2 \phi / 3$. 


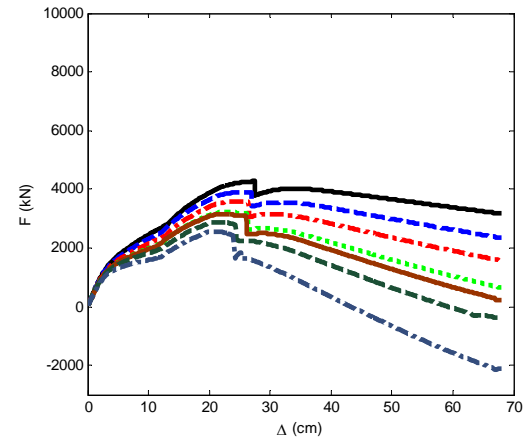

(a) Node 1

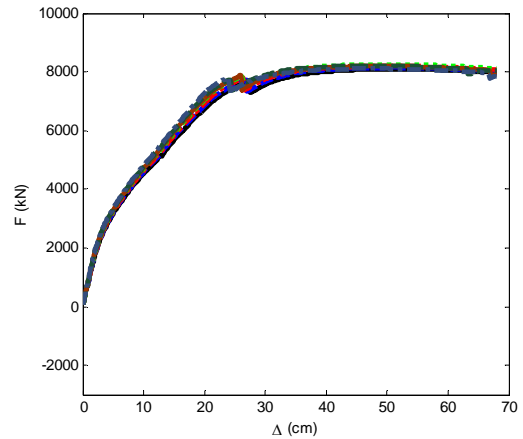

(b) Node 2

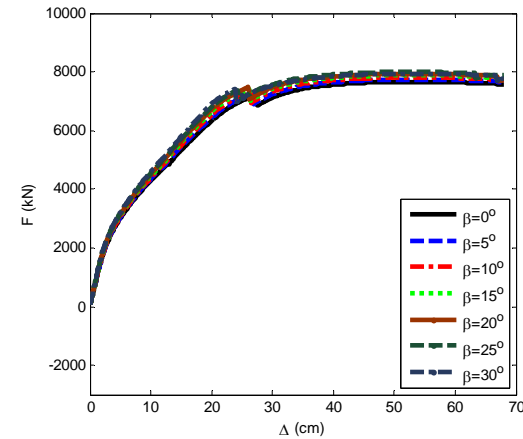

(c) Node 3

Figure 11. Pushover analyses results along the positive weak direction of the pier for Model A; the soil model is based on the log spiral method with $\delta=2 \phi / 3$.
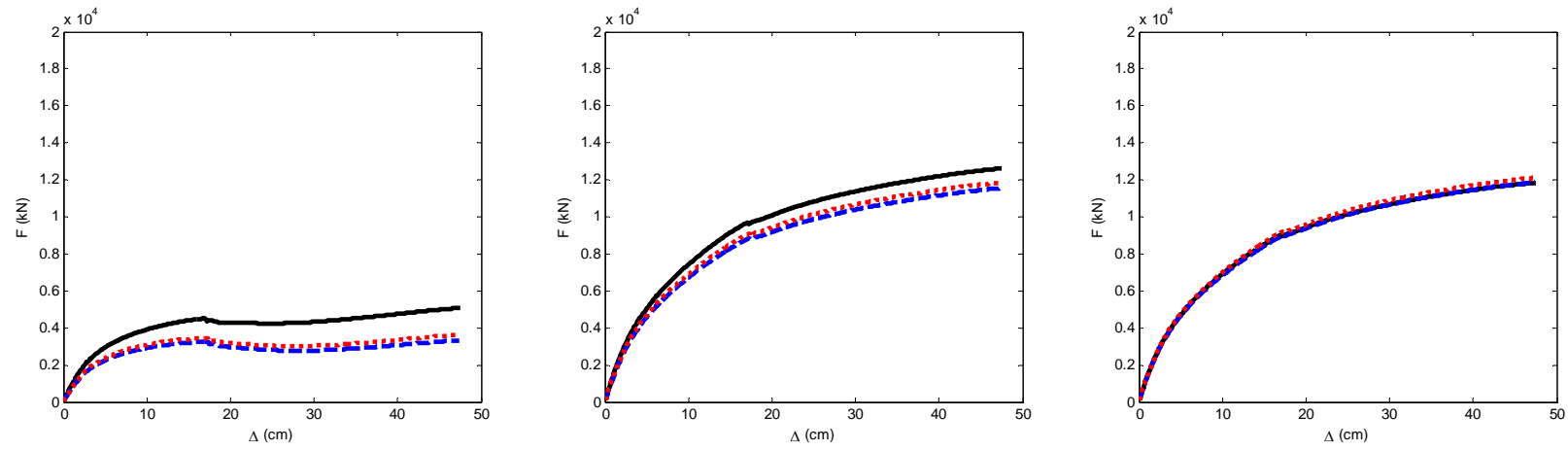

Strong direction
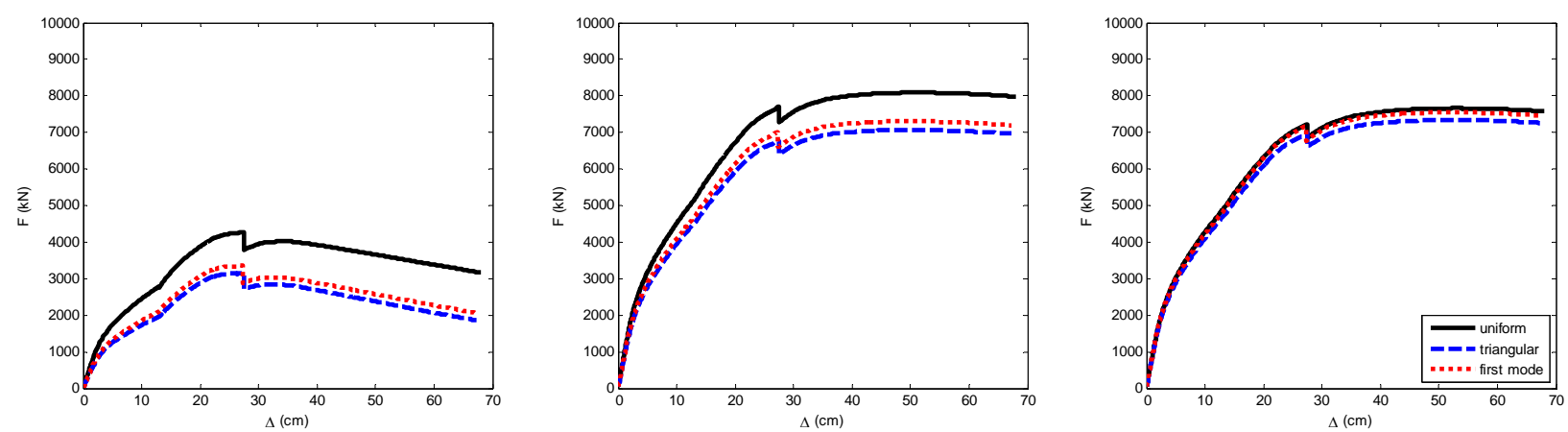

Weak direction

(a) Node 1

(b) Node 2

(c) Node 3

Figure 12. Pushover analyses results along the strong and negative weak direction of the pier for Model A considering different loading patterns; the soil model is based on the log spiral method with $\delta=2 \phi / 3$. 

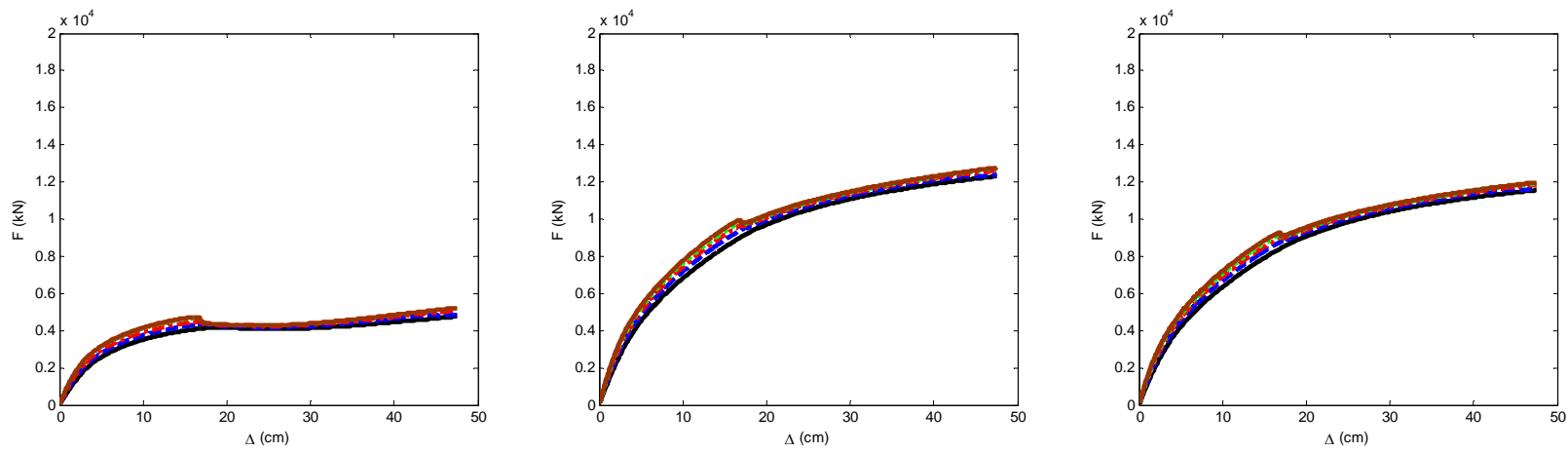

Strong direction
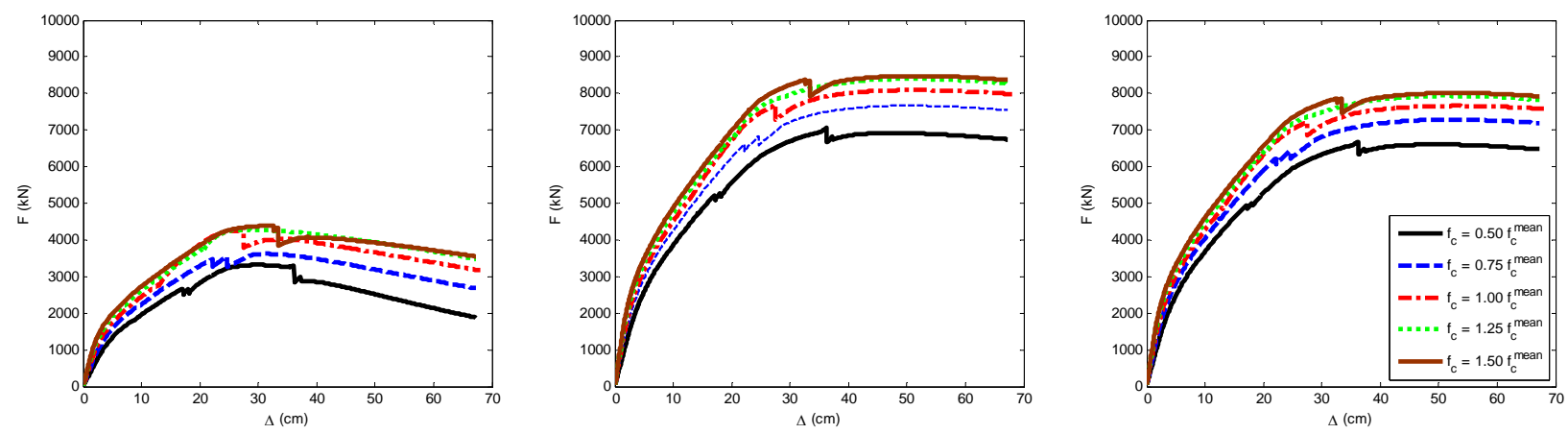

Weak direction

(a) Node 1

(b) Node 2

(c) Node 3

Figure 13. Pushover analyses results along the strong and negative weak direction of the pier for Model A considering different values for the actual compressive strength of the concrete; the soil model is based on the $\log$ spiral method with $\delta=2 \phi / 3$. 